\title{
European Society of Endocrinology Clinical Practice Guideline: Endocrine work-up in obesity
}

\author{
R Pasquali', F Casanueva ${ }^{2}$, M Haluzik ${ }^{3}$, L van Hulsteijn ${ }^{4}$, S Ledoux ${ }^{5}$, M P Monteiro6,7, J Salvador ${ }^{8,9}$, F Santini ${ }^{10}$, \\ H Toplak ${ }^{11}$ and $O$ M Dekkers ${ }^{12,13,14}$
}

${ }^{1}$ University Alma Mater Studiorum, Bologna, Italy, ${ }^{2}$ Department of Medicine, Santiago de Compostela University, Complejo Hospitalario Universitario de Santiago (CHUS), CIBER de Fisiopatologia Obesidad y Nutricion (CIBERobn), Instituto Salud Carlos III, Santiago de Compostela, Spain, ${ }^{3}$ Diabetes Centre and Centre for Experimental Medicine, Institute for Clinical and Experimental Medicine and Institute of Endocrinology, Prague, Czech Republic, ${ }^{4}$ Department of Clinical Endocrinology and Metabolism, University Medical Centre Groningen, Groningen, the Netherlands, ${ }^{5}$ Department of Physiology, Obesity Center, Louis Mourier Hospital (APHP), Colombes and Paris Diderot University, Paris, France, ${ }^{6}$ Endocrine, Cardiovascular \& Metabolic Research, Unit for Multidisciplinary Research in Biomedicine (UMIB), Instituto de Ciências Biomédicas Abel Salazar (ICBAS), University of Oporto, Porto, Portugal, ${ }^{7}$ University College of London, London, UK, ${ }^{8}$ Department of Endocrinology and Nutrition, University Clinic of Navarra, Pamplona, Spain, ${ }^{9} \mathrm{CIBEROBN}$, Instituto Carlos III, Madrid, Spain, ${ }^{10}$ Obesity and Lipodystrophy Center, University Hospital of Pisa, Pisa, Italy, ${ }^{11}$ Division of Endocrinology and Diabetology, Department of Medicine, Medical University of Graz, Graz, Austria, ${ }^{12}$ Department of Clinical Epidemiology, Leiden University Medical Centre, Leiden, the Netherlands, ${ }^{13}$ Department of Clinical Endocrinology and Metabolism, Leiden University Medical Centre, Leiden, the Netherlands, and ${ }^{14}$ Department of Clinical Epidemiology, Aarhus University Hospital, Aarhus, Denmark

Correspondence should be addressed to R Pasquali Email renato.pasquali@unibo.it

\begin{abstract}
Obesity is an emerging condition, with a prevalence of $\sim 20 \%$. Although the simple measurement of BMI is likely a simplistic approach to obesity, BMI is easily calculated, and there are currently no data showing that more sophisticated methods are more useful to guide the endocrine work-up in obesity. An increased BMI leads to a number of hormonal changes. Additionally, concomitant hormonal diseases can be present in obesity and have to be properly diagnosed - which in turn might be more difficult due to alterations caused by body fatness itself. The present European Society of Endocrinology Clinical Guideline on the Endocrine Work-up in Obesity acknowledges the increased prevalence of many endocrine conditions in obesity. It is recommended to test all patients with obesity for thyroid function, given the high prevalence of hypothyroidism in obesity. For hypercortisolism, male hypogonadism and female gonadal dysfunction, hormonal testing is only recommended if case of clinical suspicion of an underlying endocrine disorder. The guideline underlines that weight loss in obesity should be emphasized as key to restoration of hormonal imbalances and that treatment and that the effect of treating endocrine disorders on weight loss is only modest.
\end{abstract}

\section{Summary of recommendations}

The recommendations $(\mathrm{R})$ in this guideline are worded as we recommend (strong recommendation) and we suggest (weak recommendation). We formally graded only the evidence underlying recommendations for diagnostic strategies. The quality of evidence behind the recommendations is
(C) 2020 European Society of Endocrinology Printed in Great Britain classified as very low $(+000)$, low $(++00)$, moderate $(+++0)$ and strong (++++). See further section 'Summary of methods used for guideline development'. Recommendations based on good clinical practice and/or experience of the panelists were not graded. 
R.1.1. We suggest that for all patients it is of value to measure weight and height to calculate BMI, as obesity is an important condition that often remains undiagnosed. For routine care defining obesity as BMI $>30 \mathrm{~kg} / \mathrm{m}^{2}$ is sufficient as first diagnostic measure. Measuring waistcircumference can provide additional information especially if BMI $<30 \mathrm{~kg} / \mathrm{m}^{2}$.

R.1.2. We recommend that not all patients with obesity are routinely referred to an endocrinologist.

R.1.3. We recommend that weight loss in obesity is emphasized as key to restoration of hormonal imbalances.

R.1.4. We recommend taking into account drugs and dietary supplements that interfere with hormone measurements as part of the hormonal evaluation in obesity.

R.2.1. We recommend that all patients with obesity are tested for thyroid function $(+++0)$.

R.2.2. We recommend that testing for hypothyroidism is based on TSH; if TSH is elevated, free T4 and antibodies (anti-TPO) should be measured $(++00)$.

R.2.3. We do not recommend the routine measurement of FT3 in patients with elevated TSH.

R.2.4. We suggest that for obese patients the same normal hormonal values are applied as for non-obese $(+000)$.

R.2.5. We recommend that overt hypothyroidism (elevated TSH and decreased FT4) is treated in obesity irrespective of antibodies (++00).

R.2.6. We recommend against the use of thyroid hormones to treat obesity in case of normal thyroid function (++00).

R.2.7. We recommend that hyperthyrotropinaemia (elevated TSH and normal FT4) should not be treated in obesity with the aim at reducing body weight $(++00)$.

R.2.8. We suggest that for the decision to treat or not to treat hyperthyrotropinaemia, TSH level, thyroid antibodies, and age should be taken into account.

R.2.9. We suggest against the use of routine ultrasound of the thyroid gland irrespective of thyroid function.

R.3.1. We recommend that testing for hypercortisolism is not routinely applied in obesity $(++00)$.

R.3.2. In patients with clinical suspicion of hypercortisolism biochemical testing should be performed $(++00)$.

R.3.3. We recommend that in patients going for bariatric surgery (testing for) hypercortisolism should be considered.

R.3.4. We suggest that for patients with obesity the same normal values are applied as for non-obese $(+000)$.

R.3.5. We recommend not to test for hypercortisolism in patients using corticosteroids.
R.3.6. If hypercortisolism testing is considered, we recommend a $1 \mathrm{mg}$ overnight dexamethasone suppression test as first screening tool.

R.3.7. If the $1 \mathrm{mg}$ overnight dexamethasone suppression test is positive, we recommend a second biochemical test; this can be either 24-h urine cortisol or late-night salivary cortisol.

R.3.8. In all patients with confirmed hypercortisolism, an ACTH should be measured and further imaging should be performed to find the cause/source of the hypercortisolism.

R.3.9. Treatment of proven endogenous hypercortisolism is not normalizing BMI in most cases.

R.4.1. We recommend that biochemical testing for hypogonadism is not routinely applied in male obese patients; we do recommend investigating key clinical symptoms/signs of hypogonadism (++00).

R.4.2. In male patients with obesity with clinical features of hypogonadism we suggest measuring total and free testosterone (or calculated), SHBG, FSH and LH.

R.4.3. In obesity we suggest applying age-specific reference ranges for testosterone $(+000)$.

R.4.4. We recommend emphasizing the importance of weight loss to restore eugonadism in obese patients with biochemical and clinical hypogonadism.

R.4.5. We suggest that if weight loss cannot be achieved and if clinical and biochemical hypogonadism persists, treatment with testosterone can be considered in individual cases; contra-indications should be considered and other causes of hypogonadism should have been ruled out. The sole presence of obesity is not enough reason to start testosterone $(+000)$.

R.4.6. We suggest treatment with testosterone aiming at testosterone levels in the normal range $(+000)$.

R.4.7. We suggest stopping testosterone treatment if clinical features are not improving despite biochemical restoration for 6-12 months (+000).

R.4.8. We do not recommend testosterone treatment as a first therapeutic measure in hypogonadal male patients with obesity seeking fertility (+000).

R.5.1. We recommend that testing for gonadal dysfunction is not routinely applied in female patients with obesity $(++00)$.

R.5.2. We suggest to assess gonadal function in female patients with obesity with menstrual irregularities and chronic anovulation/infertility.

R.5.3. For evaluation of menstrual irregularity we suggest to assess gonadal function by measuring $\mathrm{LH}, \mathrm{FSH}$, total testosterone, SHBG, $\Delta$ 4androstenedione, oestradiol, 17-hydroxyprogesterone and prolactin. If the menstrual 
cycle is irregular but somewhat predictable, we suggest that the assessment should take place during the early follicular phase.

R.5.4. For evaluation of anovulation we suggest gonadal function to be assessed by measuring $\mathrm{LH}, \mathrm{FSH}$, oestradiol, progesterone and prolactin.

R.5.5. We recommend to assess androgen excess when PCOS is considered based on the clinical features. We suggest to measure total testosterone, free $\mathrm{T}, \Delta$ 4androstenedione and SHBG. We additionally recommend to assess ovarian morphology and blood glucose.

R.5.6. We suggest to initiate metformin treatment in women with PCOS that additionally present metabolic syndrome features $(++00)$.

R.5.7. We recommend not to start metformin with the sole aim to reduce body weight $(+000)$.

R.5.8. We recommend not to start oestrogen substitution in postmenopausal obese women with the sole aim to reduce body weight $(+000)$.

R.6.1. We recommend that testing for IGF1/GH is not routinely applied in obesity (+000).

R.6.2. We suggest testing for IGF1/GH only in patients with suspected hypopituitarism; if tested a dynamic test should be performed as a minimum $(+000)$.

R.6.3. We recommend not to use GH to treat obesity in patients with normal GH levels (+000).

R.6.4. We suggest not to perform routine tests for vitamin D deficiency in patients with obesity $(+000)$.

R.6.5. We suggest not to test for hyperparathyroidism routinely in patients with obesity $(+000)$.

R.6.6. We recommend not to test routinely other hormones, such as leptin and ghrelin, unless there is suspicion of a syndromic obesity.

R.6.7. We suggest to consider secondary causes of hypertension in the context of therapy-resistant hypertension in obesity.

\section{Obesity - a short introduction}

Obesity is an emerging condition and plays a central role in the development of non-communicable diseases like diabetes, hyperlipidaemia, hypertension, cardiovascular disease and cancer (1). Due to the tight relation with type 2 diabetes, the combination of the two diseases is often called 'diabesity' and treated accordingly (2). Following, it is important for obesity to become an integral part of medicine, and multidisciplinary European guidelines have been released (3).
The actual prevalence of obesity in most European countries is around 20\% (3). The numbers have almost tripled since 1986 when the European Association for the Study of Obesity (EASO) was founded to address the emerging obesity problem (4). There is a clear heterogeneity in the prevalence; there is however no systematic difference in prevalence between men and women (5).

Prevalence data reveal only part of the problem as BMI has been used as single indicator of overweight and obesity. If one considers that unhealthy visceral fat and/or increased body fatness is also present in a substantial amount of normal - and overweight persons, the burden of unhealthy body fat with hormonal, metabolic and disease implications is even higher (6). Although the simple measurement of BMI is likely an overtly simplistic approach to obesity, we use a BMI-based definition of obesity (BMI $>30.0 \mathrm{~kg} / \mathrm{m}^{2}$ ) throughout this guideline. The main reason is that BMI is easily calculated in clinical practice and also because there are currently no data showing that more sophisticated methods are more useful to guide the endocrine work-up in obesity.

Increased body fatness leads to a number of hormonal changes, the most obvious example being insulin resistance. Additionally, concomitant hormonal diseases can be present and have to be properly diagnosed - which in turn might be more difficult due to alterations caused by body fatness itself. The two-way relationship between obesity and hormones, obesity as cause and consequence of hormonal alterations, is conceptually shown in Fig. 1. The main hormonal alterations in obesity are shown in Table 1 . Different diseases that potentially cause obesity are listed in Table 2.

The present European Society of Endocrinology Clinical Guideline is focused on the endocrine work-up in patients with obesity; although not its main focus we do discuss the potential therapeutic consequences of hormonal alterations in patients with obesity. We do not to focus on syndromic obesity.

\section{Methods}

\subsection{Guideline working group}

This guideline was developed by The European Society of Endocrinology (ESE). The chairs of the working group, Renato Pasquali and Olaf Dekkers (methodological expert), were appointed by the ESE Clinical Committee. Hermann 


\section{Concept of hormonal causes and consequences in obesity}

\author{
Effect treating \\ endocrine disease \\ on obesity
}

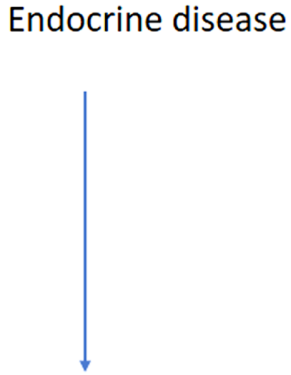

Obesity
Obesity

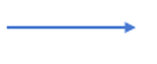
Effect treating obesity on hormonal dysfunction

\section{Figure 1}

Reciprocal interactions between obesity and endocrine diseases, including potential contribution of treatment.

Toplak served as representative of the European Association of the Study of Obesity (EASO). The multidisciplinary team consisted of the following experts: Renato Pasquali (Italy), Mariana P Monteiro (Portugal), Felipe Casanueva (Spain), Ferruccio Santini (Italy), Martin Haluzik (Czech Republic), Severine Ledoux (France), Javier Salvador (Spain), Hermann Toplak (Austria), Olaf Dekkers (Netherlands, methodology) and Leonie van Hulsteijn (Netherlands, methodology). The working group had two in-person meetings (February 2018 and September 2018). Consensus was reached upon discussion; minority positions were taken into account in the rationale behind recommendations.

\subsection{Target group}

This guideline was developed for healthcare providers involved in the care of patients with obesity, which covers a broad range of doctors. In line, the guidelines were not developed with the specific aim to cover rare forms of obesity.

\subsection{Aims}

The overall purpose of this guideline is to provide clinicians with practical guidance for the endocrine work-up in obesity. In clinical practice, diagnostic - and treatment decisions should take into account the recommendations but also the clinical judgment of the treating physician. Recommendations are thus never meant to replace clinical judgment.

\subsection{Summary of methods used for guideline development}

The methods used have been described in more detail previously (11). In short, the guideline used GRADE (Grading of Recommendations Assessment, Development and Evaluation) as a methodological base. The first step was to define the clinical questions (see Section 3.5), the second a systematic literature search (see Section 3.6). The quality of evidence behind the recommendations is classified as very low $(+000)$, low $(++00)$, moderate $(+++0)$ and strong $(++++)$. Two problems hampered a formal grading of the evidence for endocrine testing in obesity: the lack of reference standard for most endocrine conditions in obesity; the presence of such reference standard is crucial when formally grading studies on diagnostics (12). Secondly, grading for diagnostic strategies is possible, it requires, however, that studies compare different 
Table 1 Hormonal alterations in obesity.

\begin{tabular}{ll}
\hline Hormone & Levels in obesity \\
\cline { 2 - 2 } TSH & N or $\uparrow$ \\
FT4 & N or slightly $\downarrow$ \\
Cortisol (blood and urine, salivary) & N or $\uparrow$ \\
ACTH & Altered suppression tests \\
Growth hormone & Nor $\uparrow$ \\
IGF-1 & Nor $\downarrow$ \\
& N or $\downarrow$ \\
Prolactin & $?$ \\
Testosterone (male) & $\downarrow$ \\
Testosterone (female) & $\downarrow$ \\
LH/FSH & $\uparrow$ \\
& $\downarrow$ in men \\
25-OH vitamin D & $\uparrow$ LH in women \\
& $\downarrow$ \\
PTH & \\
Insulin & N or $\uparrow$ \\
Renin & $\uparrow$ \\
Aldosterone & $\uparrow$ \\
GLP-1 & $\uparrow$ \\
Leptin & $\downarrow$ \\
Ghrelin & $\uparrow$ \\
\hline
\end{tabular}

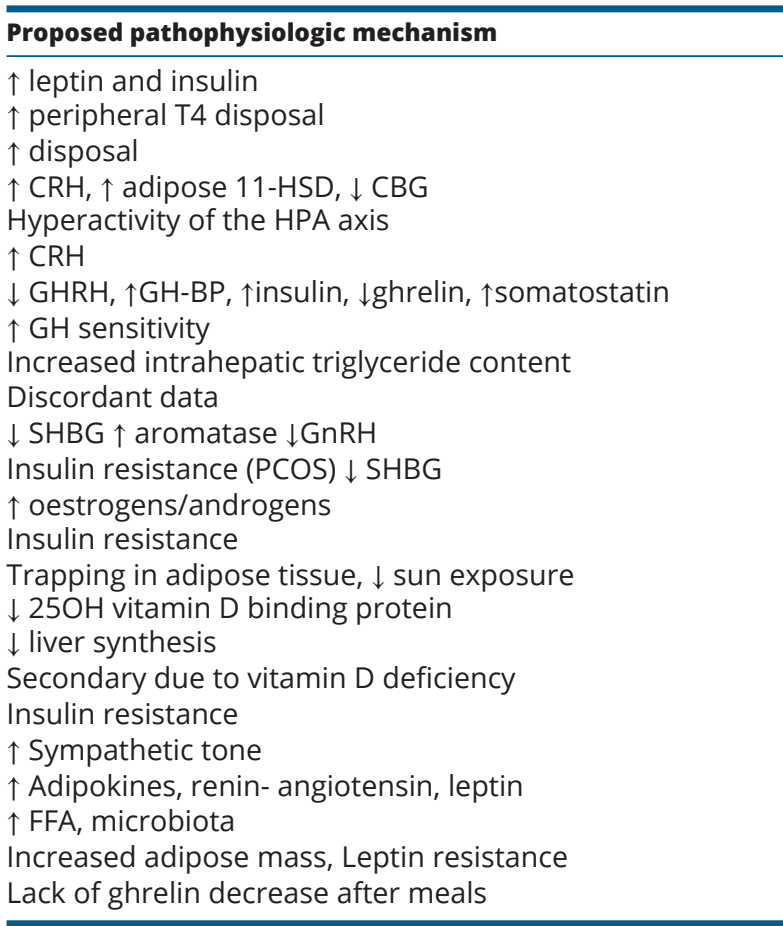

11-HSD, 11 $\beta$-hydroxysteroid dehydrogenase; ACTH, adrenocorticotropic hormone; CBG, corticosteroid-binding globulin; CRH, corticotropin-releasing hormone; FFA, free fatty acids; FSH, follicle-stimulating hormone; FT4, free thyroxine; GH-BP, growth hormone-binding protein; GHRH, growth hormonereleasing hormone; GLP, glucagon-like peptide; GnRH, gonadotropin-releasing hormone; HPA, hypothalamic-pituitary-adrenal axis; IGF, insulin-like growth factor; LH, luteinizing hormone; PCOS, polycystic ovary syndrome; PTH, parathyroid hormone; SHBG, sex hormone-binding globulin; TSH, thyroid-stimulating hormone.

strategies with respect to clinical effectiveness and harms (12). Such studies have not been performed in obesity.

For the recommendations we took into account: (1) quality of the evidence, (2) balance of desirable and undesirable outcomes, (3) values and preferences (patient preferences, goals for health, costs, feasibility of implementation, etc.), (4) clinical experience of the panel $(13,14)$. The recommendations are worded as recommend (strong recommendation) and suggest (weak recommendation). The meaning of a strong recommendation can be stated as follows: reasonably informed persons (clinicians, politicians and patients) would want the management in accordance with the recommendation. For a weak recommendation, most persons would still act in accordance with the guideline, but a substantial number would not (14). Recommendations based on good clinical practice and experience of the panelists were not graded (15). Recommendations were derived from majority consensus of the guideline development committee.
All recommendations are accompanied by text explaining why specific recommendations were made.

\subsection{Clinical questions, eligibility criteria and endpoint definition}

The present guideline is primarily about the endocrine work-up in obesity, that is, about diagnostic questions. Although diagnostic strategies can be compared in a randomized trial (i.e. what diagnostic test is associated with the best morbidity and mortality outcome), to the knowledge of the panel no such trials in obesity were published. The guideline panel considered a systematic review on the prevalence of most common endocrine disorders in obesity to be relevant as evidence base for the guideline. A literature search and systematic review on the prevalence of thyroid disorders, autonomous cortisol secretion, hypogonadism (males) and hyperandrogenism (females) was subsequently performed (Table 3). This review is summarized below, and published as stand-alone paper (16). 
Table 2 Examples of endocrine diseases/disturbances causing or contributing to obesity.

Condition

Androgen excess (women)

Cushing's disease or Cushing's syndrome

Drug-induced endocrine dysfunction (e.g. lithium, anti-depressants, antipsychotics, glucocorticoids...)

Ovarian failure (premature or menopause)

Prevalence in obesity

Common

Common

Rare

Common

Premature uncommon

Physiological (Menopause) Common

GH deficiency Rare

Hypopituitarism

Rare

Hypothalamic obesity associated with Extremely rare Genetic Syndromes

Hypothalamic obesity acquired (hypothalamic lesions or, tumors)

(Severe) hypothyroidism

Insulinoma

Leptin deficiency

Leptin receptor deficiency or inactive leptin (8)

MC4R mutation

Primary empty sella

Abnormal processing of Propiomelanocortin (POMC) gene mutations

Prohormone convertase $1 / 3$ deficiency (PC-1/3) (PCSK1 gene mutation)

Pseudohypoparathyroidism Type 1a Rare (Albright hereditary osteodystrophy)
Rare

Very rare

Rare

Extremely rare

Extremely rare

rare

Rare (increase intracranial pressure)

Extremely rare

Extremely rare

\section{When to think about it}

Severe obesity

Symptoms and signs of hypogonadism

Central obesity

Irregular menses

Hirsutism

Acanthosis nigricans

Central obesity

Hypertension

Type 2 diabetes

Psychiatric disorders

Glucocorticoid therapy

Secondary amenorrhea Vasomotor symptoms

Vaginal mucosa atrophy

Hypothalamic or pituitary disease, pituitary or hypothalamic surgery or radiation therapy

Suspicion of hypothalamic obesity Surgery or radiotherapy in pituitary region

Hypogonadism (hypogonadism or hypergonadotropic) or variable gonadal function. dysmorphic syndrome, mental and grow retardation

Severe hyperphagia

Possible multiple endocrine abnormalities

Mixedematous features

Concurrent autoimmune diseases

Hypoglycaemic symptoms

Severe childhood obesity

Severe childhood obesity

Severe childhood obesity female, HTA, SAOS headache, menstrual disturbances

Severe childhood obesity Red hair

Multiendocrine disorders, including diabetes insipidus, growth hormone deficiency, primary hypogonadism, adrenal insufficiency and hypothyroidism (10)

Short stature, short fourth metacarpal bones, obesity, s.c. calcifications, developmental delay
First diagnostic procedure

LH FSH testosterone

LH FSH oestradiol testosterone

$1 \mathrm{mg}$ ODST

$1 \mathrm{mg}$ ODST to exclude Cushing syndrome (except in glucocorticoid use)

FSH, LH, oestradiol

Serum IGF-I, GH-stimulating tests

FT4 TSH LH FSH (testosterone or estradiol)

GH IGF-1 PRL

ACTH stimulation test

$\mathrm{GH}$ stimulation test

Leptin (leptin resistance) (7); genetic testing

Brain CT or MRI

FT4 TSH

Blood glucose, insulin, C-peptide 72-h supervised fast

Leptin $\downarrow$

Leptin $\uparrow$

Leptin normal or $\uparrow$

Prolactin, FSH LH, testosterone/ oestradiol, cortisol, IGF-1

MRI of pituitary

$\mathrm{ACTH} \downarrow$ (9)

PTH $\uparrow$ calcium $\downarrow$ phosphate $\uparrow$

ACTH, adrenocorticotropic hormone; FSH, follicle-stimulating hormone; FT4, free thyroxine; GH, growth hormone; IGF, insulin-like growth factor; LH, luteinizing hormone; MC4R, melanocortin receptor 4; ODST, overnight dexamethasone suppression test; PCSK, proprotein convertase subtilisin/kexin; PTH, parathyroid hormone; TSH, thyroid-stimulating hormone. 


\subsection{Description of search and selection of literature}

A literature search of electronic medical databases was performed. We only considered papers with $>10$ patients included, as obesity is not a rare condition and studies with $<10$ patients probably suffer from selection bias. For all papers considered obesity was defined as BMI $\geq 30$ $\mathrm{kg} / \mathrm{m}^{2}$ and/or large waist circumference as expression of abdominal obesity (definition of enlargement based on different criteria used in included articles). Overall, 3819 potentially relevant papers were considered; 68 were included (two studies assessed both hypothyroidism and hypercortisolism (16)).

\subsection{Review process and endorsement of other societies}

A draft of the guideline was reviewed by the experts in the field; it was also submitted for comments by ESE members. All comments and suggestions were then discussed and implemented as appropriate by the panel.

\section{Summary of results from the systematic review}

For details of the review see (16). In summary, the prevalence of hypothyroidism in obesity was $14.0 \%$ (95\% CI: 9.7-18.9), based on 19 studies; the prevalence of subclinical hypothyroidism was found 14.6\% (95\% CI: 9.2-20.9), also based on 19 studies. For both clinical and subclinical hypothyroidism, the reported prevalence ranged considerably between included studies, suggesting underlying clinical heterogeneity.

For hypercortisolism, we found an overall low prevalence of $0.9 \%$ (95\% CI: $0.3-1.6)$, based on 22 studies. For male hypogonadism, based on free testosterone measurements, the pooled prevalence was found to be $32.7 \%$ (95\% CI: 23.1-43.0); the reported prevalence in the 11 included papers ranged from 16 to $52 \%$, also suggesting underlying heterogeneity. For hyperandrogenism in females, reported prevalences of PCOS ranged from 9.1 to $25 \%$ (three studies), which is higher than expected (17).

Table 3 Clinical questions and metrics of the review.

\begin{tabular}{|c|c|c|c|c|}
\hline \multirow[b]{2}{*}{ Clinical question } & \multicolumn{3}{|c|}{ Predefined selection criteria and key outcome parameters } & \multirow{2}{*}{$\begin{array}{c}\text { Number of } \\
\text { studies included }\end{array}$} \\
\hline & Population & Restriction & Outcome & \\
\hline $\begin{array}{l}\text { Question 1A: What is the } \\
\text { prevalence of overt } \\
\text { hypothyroidism in } \\
\text { obesity? } \\
\text { Question 1B: What is the } \\
\text { prevalence of subclinical } \\
\text { hypothyroidism in } \\
\text { obesity? }\end{array}$ & Obese patients & $\begin{array}{l}\text { Data on subclinical/overt hypothyroidism } \\
\text { based on raised TSH (definition of } \\
\text { positive test based on cut-off values } \\
\text { used in included articles) }\end{array}$ & $\begin{array}{l}\text { Prevalence of } \\
\text { subclinical/overt } \\
\text { hypothyroidism }\end{array}$ & 27 \\
\hline $\begin{array}{l}\text { Question 2: What is the } \\
\text { prevalence of } \\
\text { hypercortisolism in } \\
\text { obesity? }\end{array}$ & Obese patients & $\begin{array}{l}\text { Data on hypercortisolism based on } \geq 2 \\
\text { of the following measurements: UFC } \\
\text { greater than the normal range for the } \\
\text { assay, elevated LNSC, elevated serum } \\
\text { cortisol after ODST or after LDDST } \\
\text { (definition of positive test based on } \\
\text { cut-off values used in included } \\
\text { articles) }\end{array}$ & $\begin{array}{l}\text { Prevalence of } \\
\text { hypercortisolism }\end{array}$ & 22 \\
\hline $\begin{array}{l}\text { Question 3: What is the } \\
\text { prevalence of } \\
\text { hypogonadism in } \\
\text { male patients with } \\
\text { obesity? }\end{array}$ & $\begin{array}{c}\text { Obese male } \\
\text { patients }\end{array}$ & $\begin{array}{l}\text { Data on hypogonadism based on low TT } \\
\text { or FT (definition of positive test based } \\
\text { on cut-off values used in included } \\
\text { articles) }\end{array}$ & $\begin{array}{l}\text { Prevalence of } \\
\text { hypogonadism }\end{array}$ & 18 \\
\hline $\begin{array}{l}\text { Question 4: What is the } \\
\text { prevalence of } \\
\text { hyperandrogenism in } \\
\text { female patients with } \\
\text { obesity? }\end{array}$ & $\begin{array}{l}\text { Obese female } \\
\text { patients }\end{array}$ & $\begin{array}{l}\text { Data on hyperandrogenism based on } \\
\text { raised TT or FT (definition of positive } \\
\text { test based on cut-off values used in } \\
\text { included articles) }\end{array}$ & $\begin{array}{l}\text { Prevalence of } \\
\text { hyperandrogenism }\end{array}$ & 3 \\
\hline
\end{tabular}

$\mathrm{BMI}$, body mass index; FT, free testosterone; LDDST, low-dose dexamethasone suppression test; LNSC, late night salivary cortisol; ODST, overnight dexamethasone suppression test; TSH, thyroid-stimulating hormone; TT, total testosterone; UFC, urine free cortisol; WC, waist circumference. 


\subsection{General recommendations}

R.1.1. We suggest that for all patients it is of value to measure weight and height to calculate BMI, as obesity is an important condition that often remains undiagnosed. For routine care defining obesity as BMI $>30 \mathrm{~kg} / \mathrm{m}^{2}$ is sufficient as first diagnostic measure. Measuring waist-circumference can provide additional information especially if BMI $<30 \mathrm{~kg} / \mathrm{m}^{2}$.

\section{Reasoning:}

Obesity, defined by a BMI $>30 \mathrm{~kg} / \mathrm{m}^{2}$, is in most cases associated with high fat mass and thus BMI is considered an adequate indicator of obesity and sufficient as first diagnostic measure. Furthermore, a grading in obesity I $\left(>30 \mathrm{~kg} / \mathrm{m}^{2}\right)$, obesity II $\left(>35 \mathrm{~kg} / \mathrm{m}^{2}\right)$ and obesity III $(>40$ $\mathrm{kg} / \mathrm{m}^{2}$ ) is proposed and should be used in clinical practice. Recently, EASO has suggested to grade further with obesity IV-VI accordingly (6) because of the increasing prevalence of obesity related complications with more severe obesity. Especially in subjects with $\mathrm{BMI}<30 \mathrm{~kg} / \mathrm{m}^{2}$ increased body fat mass (with sarcopenia) may be suggested by increased waist circumference (in Caucasian females a waist $<80 \mathrm{~cm}$ is regarded normal, $80-88 \mathrm{~cm}$ as elevated and $>88 \mathrm{~cm}$ is regarded equally important as a BMI $>30 \mathrm{~kg} / \mathrm{m}^{2}$, in males the respective cut-offs are 94 and $102 \mathrm{~cm}$ ). In clinical practice these measures can be easily achieved. Detailed phenotyping may include BIA (Bioelectrical impedance analysis) measurements, DXA (Dual-energy X-ray absorptiometry) Scans or BOD-POD (air displacement plethysmography) measurements (3).

R.1.2. We recommend that not all patients with obesity are routinely referred to an endocrinologist.

\section{Reasoning:}

In most cases, despite obesity being a condition of endocrine and metabolic imbalance, obesity is not caused by other endocrine diseases or hormonal disturbances. Furthermore, the prevalence of obesity is such that standard referral to an endocrinologist would not be compatible with available resources in most countries. The endocrinologist should be consulted in case of clear suspicion of an endocrine disease (e.g. endogenous hypercortisolism, hypogonadism in males or androgen excess in women). In addition, because the prevalence of endocrine disturbances is related to obesity severity, and because clinical signs and symptoms of endocrine conditions can be difficult to distinguish from obesity, we suggest that in patients with morbid obesity a referral to an endocrinologist is considered. Further reasons for referral to the endocrinologist include therapy-resistant obesity and /or rapid weight gain and candidates for bariatric surgery.

R.1.3. We recommend that weight loss in obesity is emphasized as key to restoration of hormonal imbalances.

\section{Reasoning:}

For most hormones (TSH, cortisol. testosterone), the proper equilibrium is usually restored following weight reduction, irrespective of therapeutic strategy (see following chapters for details).

R.1.4. We recommend taking into account drugs and dietary supplements that interfere with hormone measurements as part of the hormonal evaluation in obesity.

\section{Reasoning:}

Beside general drugs used to manage obesity complications, several dietary supplements are commonly taken by patients with obesity, with the aim of facilitating weight loss or well-being, controlling glucose metabolism or preventing cardiovascular events. Some of these exogenous substances may interfere with the regulation of various hormonal axes as well as with hormonal assays $(2,18,19)$.

\subsection{Testing for thyroid function}

R.2.1. We recommend that all patients with obesity are tested for thyroid function $(+++0)$.

\section{Reasoning:}

Thyroid function is commonly assessed, independently of obesity, because hypothyroidism is one of the most common endocrine diseases. In Europe, the prevalence of overt hypothyroidism varies between 0.2 and 5.3\% (20) and that of subclinical hypothyroidism between 4 and $10 \%$ (21); the prevalence of undiagnosed hypothyroidism in Europe was estimated around 5\% (22).

Symptoms of hypothyroidism (such as fatigue, depression, cramps, menstrual disturbance or weight gain) are nonspecific (23) and can be confused with those of obesity. Hypothyroidism can be easily diagnosed by blood tests. Screening of the general population is mostly not recommended (24), although some populations at risk, have been identified; interestingly, obesity is not among these conditions $(20,24)$, but the usefulness to test TSH in obesity was recently suggested (25). Furthermore, 
TSH screening is recommended in patients with severe obesity before bariatric surgery. A higher prevalence of subclinical hypothyroidism in obesity has been shown. Notably, one study noted a tenfold increase of either overt or subclinical hypothyroidism compared to the general population (26). In our meta-analysis (16), the prevalence of hypothyroidism in obesity was $14.0 \%$ (95\% CI $9.7-$ 18.9); the prevalence of subclinical hypothyroidism was found $14.6 \%$ (95\% CI 9.4-20.9).

Thyroid function is frequently assessed in patients with obesity with the hope to identify a cause of obesity and/or a reason for resistance to weight loss efforts. Certainly, thyroid hormones have an important role in energy metabolism and hypothyroidism could indeed induce weight gain by means of both an increasing fat mass, due to mild decrease in resting energy expenditure and reduced physical activity, and also fluid retention, due to glycosaminoglycans accumulation $(20,27)$. However, despite weight gain being a frequent complaint in hypothyroidism (28), it is usually of limited extent (27). In line, treatment of overt hypothyroidism produces only a modest weight loss (usually of less than $10 \%)(29,30,31)$, indicating that severe obesity is usually not secondary to hypothyroidism. Several studies have shown a positive association between TSH and BMI $(32,33)$ and some studies suggested that small variations of thyroid hormones, even in the normal range, may promote weight gain (34) or impair weight loss induced by diet (35) or bariatric surgery (36). However, some longitudinal studies suggest that changes in thyroid hormones are side effects of increasing body weight (BW) rather than the cause (37). Furthermore, abnormal thyroid function usually improves after weight loss obtained by calorie restriction $(38,39)$ or by bariatric surgery $(21,36)$. This suggests that in obesity the increase in serum TSH (in the absence of thyroid autoantibodies) is likely an adaptive response (40) rather than the primary event (see also 5.2.4) (41). Thus, hyperthyrotropinaemia associated with obesity must be differentiated from auto-immune-related subclinical hypothyroidism.

No study directly assessed the benefits and harms of screening versus no screening in obese populations (42). However, if 'true' hypothyroidism is present, it potentiates the risk of obesity to develop cardiovascular risk factors and features of metabolic syndrome (21). Hypothyroidism contributes to an unfavorable lipid profile, and thus, potentially increases vascular risk (43, 44). Finally, untreated hypothyroidism could blight the attempts at loosing body weight.
In conclusion, because hypothyroidism is rather prevalent and could potentiate weight gain and worsen comorbidities in obesity, and because assessment is simple and treatment is inexpensive and safe, we recommend to assess thyroid function in obesity.

\section{R.2.2. We recommend that testing for hypothyroidism is based on TSH; if TSH is elevated, free $T 4$ and antibodies (anti-TPO) should be measured $(++00)$.}

\section{Reasoning:}

According to American guidelines (45), TSH is the best screening test for thyroid dysfunction for the vast majority of clinical situations, in which normal TSH is enough to rule out primary hypothyroidism. Central hypothyroidism, with low-to-normal TSH concentrations and a disproportionately low concentration of fT4, is rare representing less than $1 \%$ of cases of hypothyroidism (46). Thus, fT4 has to be measured only if TSH is elevated or if disorders other than primary hypothyroidism are suspected, notably if there is a suggestion of pituitary disease, thyroid hormone resistance syndrome, or symptoms of hypothyroidism with normal TSH (46). In these situations, free T4 should be measured instead of total T4 (45).

The most common cause of hypothyroidism is chronic autoimmune thyroiditis. Raised concentrations of thyroid antibodies are detected in about $11 \%$ of the general population (47), while studies in obesity have provided conflicting results $(48,49)$. Thyroid antibody profiles are helpful to diagnose autoimmune hypothyroidism and to determine patients at risk of developing hypothyroidism. In patients with increased TSH, thyroid peroxidase (TPO) antibodies can predict progression to overt disease, with TPO antibodies levels $>500 \mathrm{IU} / \mathrm{mL}$ indicating an increased risk to progress $(27,49)$. Thus, assessment of TPO antibodies is recommended in case of subclinical hypothyroidism (45). Although there is discussion about the value of thyroglobulin antibodies (25), especially in the context of obesity, the evidence is currently too weak to recommend testing for thyroglobulin antibodies (50); in individual cases, thyroglobulin testing can be considered.

\section{R.2.3. We do not recommend the routine measurement of FT3 in patients with elevated TSH.}

\section{Reasoning:}

Measurement of total or free triiodothyronine (T3) is not useful to detect hypothyroidism (20) as levels are 
often normal due to hyperstimulation of the remaining functioning thyroid tissue by elevated TSH. Moreover, FT3 level is difficult to interpret because many acute or chronic extra-thyroidal conditions (involving nutritional status and systemic inflammation) can reduce the conversion of T4 to T3, a mechanism known as 'nonthyroidal illness', 'euthyroid sick syndrome' or 'low-T3 syndrome' (51). There are very few data on the incidence of non-thyroidal illness in the obese population but one publication suggested that inflammation may increase non-thyroidal illness in obesity (52). In contrast, FT3 has been described to be higher in obesity than in lean people, this being mainly related to the nutritional status (53). This shows that the interpretation of FT3 in obesity is not straightforward.

\section{R.2.4. We suggest that for obese patients the same normal hormonal values are applied as for non- obese (+000).}

\section{Reasoning:}

The definition of hypothyroidism is based on statistical reference ranges $(20,45)$, the reference range for thirdgeneration TSH assays being laboratory specific. This upper limit is typically around $4 \mathrm{mIU} / \mathrm{L}$ in the general population (45). Obesity is associated with modifications of thyroid parameters: TSH levels are usually higher than in normal-weight, age- and gender-matched individuals and are correlated with BMI (48). The relation of BMI with FT3 and FT4 is inconsistent, but a negative relation between BMI and FT4 and a positive relation between BMI and FT3 with a decrease FT4/FT3 ratio have been described $(48,53)$. The TSH elevation could reflect decrease in thyroid hormones concentrations, explained by an increased plasmatic volume or increased rate of thyroid hormone disposal in obesity, causing in turn a compensatory activation of the pituitary-thyroid axis (54). This interpretation is in line with lower FT4 levels in obesity, together with the need for higher doses of substitutive L-thyroxine in hypothyroid patients with obesity. Other mechanisms proposed to explain these modifications include increases in leptin and insulin (27).

Some authors argue for specific norms in obesity. Notably, in a large cross-sectional study, TSH ranges were estimated as $0.6-5.5 \mathrm{mIU} / \mathrm{L}$ in the normal-weight category and $0.7-7.5 \mathrm{mIU} / \mathrm{L}$ in the morbid obesity category. This study showed that, by using the normalweight ranges, the prevalence of high TSH levels increased threefold in the morbid obesity category (53). However, no compelling evidence has been provided that using specific reference values for the obese population would help to identify patients with thyroid dysfunction who need treatment.

\section{R.2.5. We recommend that overt hypothyroidism (elevated TSH and decreased FT4) is treated in obesity irrespective of antibodies $(++00)$.}

\section{Reasoning:}

Although the issue is still controversial (55), treatment with levothyroxine substitution should be considered in case of overt hypothyroidism, or in mild hypothyroidism with $\mathrm{TSH}>10 \mathrm{mIU} / \mathrm{L}$, in line with current guidelines (45). L-thyroxine is the hormone of choice; no additional benefits have been demonstrated of L-thyroxine and L-triodothyronine combination (56). If laboratoryspecific normal values are not available, a TSH target of $0.45-4.12 \mathrm{mIU} / \mathrm{L}$ should be considered (45). The initial L-thyroxine dose should be assigned on the basis of the thyroid hormone levels and clinical situation (45) and subsequently adjusted by periodic assessment of serum TSH. FT3 and FT4 measurement are not recommended for treatment monitoring. Caution in the choice of the starting dose and in dose escalation should be used in patients with long-lasting, overt hypothyroidism, particularly the elderly and/or with cardiovascular disease.

In obesity, treatment of hypothyroidism is followed by a mild increase in resting energy expenditure (34) but only a modest weight loss is achieved (29), mainly determined by excretion of excess body water. The target of TSH is the same as in the general population and should not be adjusted with the aim at reducing BMI. The L-thyroxine dose is usually to be reduced after weight loss achieved by bariatric surgery (57).

\section{R.2.6. We recommend against the use of thyroid hormones to treat obesity in case of normal thyroid function $(++00)$.}

\section{Reasoning:}

Thyroid hormone preparations and their derivatives have been extensively employed in the past century as antiobesity drugs (the first clinical reports on the weightlowering effect of sheep-derived thyroid extracts date from the 1890s) and sometimes are still inappropriately prescribed, despite specific recommendations against their use in euthyroid obese subjects (45). The rationale for this misuse stems from the well-known link between thyroid hormones and resting energy expenditure, which in popular fallacy is often translated into a link between hypothyroidism and obesity. Furthermore, the reduction in FT3 levels during caloric deprivation has been advocated as a possible cause for failure of hypocaloric diets. Several 
studies have been performed to investigate the ability of thyroid hormone or their analogues to favour weight loss, without producing adverse effects due to iatrogenic thyrotoxicosis $(58,59,60)$. Overall, these studies have demonstrated only minor effects in terms of efficacy, while increased urinary nitrogen excretion has been observed, indicating loss of fat-free tissue beside the occurrence of adverse effects on bone metabolism and affective status. Furthermore, excessive thyroid hormone in patients with obesity already at risk for cardiovascular disease may facilitate the onset of cardiac arrhythmia, heart failure or ischemic events (61). Apart from decreasing body weight, thyroid hormone also improves hepatic lipid metabolism, which was also used as an argument for use in obesity. The development of TR $\beta$-selective agonist supposed to improve metabolic parameters without affecting heart rate did not have a conclusive outcome and the combined peptides that deliver FT3 specifically in the liver are not yet developed (62).

\section{R.2.7. We recommend that hyperthyrotropinaemia (elevated TSH and normal FT4) should not be treated in obesity with the aim at reducing body weight (++00).}

\section{Reasoning:}

A slightly increased TSH $(<10 \mathrm{mIU} / \mathrm{L})$ in the presence of normal FT4 is a common finding in obesity, and on its own is not enough to diagnose a condition of primary hypothyroidism. The Whickham survey estimated that annual progression of subclinical hypothyroidism to overt hypothyroidism occurs in 2-5\% (63) and the rate may be lower in obesity (64). Very few clinical trials have studied the potential benefits and the safety of L-thyroxine treatment in the obese population. Randomized controlled trials reported no relevant difference in BMI with levothyroxine treatment compared with placebo in subclinical hypothyroidism (42). A recent meta-analysis showed that treatment of subclinical hypothyroidism does not improve clinical symptoms such as overweight or quality of life (65). Harms of treatment were poorly studied and sparsely reported, and low TSH values are frequently found in patients treated with L-thyroxine potentially causing side effects. Indeed, between 10 and 33\% of individuals on L-thyroxine therapy have TSH values below normal and approximately one third to one half of these TSH levels are less than $0.1 \mathrm{mIU} / \mathrm{L}$ (66).

Patients with obesity often complain of symptoms suggestive of hypothyroidism that may prompt the practitioner to introduce thyroid hormone treatment.
As argued, thyroid hormone treatment should not be initiated only based on the finding of hyperthyrotropinaemia, since weight loss is unlikely and may deter the patient seeking appropriate management of their obesity.

\section{R.2.8. We suggest that for the decision to treat or not to treat hyperthyrotropinaemia, TSH level, thyroid antibodies, and age should be taken into account.}

\section{Reasoning:}

A more pronounced elevation of TSH is related to higher risk of developing hypothyroidism (67). Although there is a general agreement that hypothyroidism with TSH levels above $10 \mathrm{mIU} / \mathrm{L}$ should be treated (45), whether and which patients with TSH levels of 4.5-10 mIU/L benefit is less certain. For the decision on starting treatment of mild hypothyroidism other considerations should be taken into account. The presence of thyroid autoimmunity (see 5.2.2), or coexistence of other causes of primary hypothyroidism (e.g. previous radioiodine treatment for hyperthyroidism or a history of destructive thyroiditis), particularly in a young subject or in a woman in fertile age should prompt L-thyroxine treatment. By contrast, older age ( $>70$ years) particularly in the presence of concurrent (cardiovascular) diseases, should direct the decision toward a follow-up strategy (45). L-thyroxine replacement therapy is recommended for older patients in good health status with TSH $>10$ mIU/L (68). The link between mild hypothyroidism and coronary heart disease is generally observed in the youngest population only and on the contrary, cohort studies have demonstrated that extreme longevity is associated with higher TSH levels (68). In addition, in the 'Trust Thyroid Trial', levothyroxine provided no apparent benefits on clinical symptoms in older persons with subclinical hypothyroidism (69), but no specific trial was performed in old obese persons.

Among women of reproductive age, subclinical hypothyroidism has been associated with infertility, an increased risk of adverse pregnancy and neonatal outcomes, and possibly with an increased risk of neurocognitive deficits in offspring. There is evidence that T-thyroxine therapy decreases the risk for pregnancy loss and preterm delivery in pregnant women with TSH $>4.0$ $\mathrm{mIU} / \mathrm{L}$ (70). The ATA recommendations propose to treat women of childbearing age who are pregnant or planning a pregnancy, if they have positive levels of serum TPOAb and their TSH is $>2.5 \mathrm{mIU} / \mathrm{L}$ (45). During pregnancy, the target range for TSH should be based on trimester-specific ranges (around $2.5 \mathrm{mIU} / \mathrm{L}, 3 \mathrm{mIU} / \mathrm{L}$ and $3.5 \mathrm{mIU} / \mathrm{L}$ at the first, second and third trimester, respectively). However, 
no study was specifically conducted in obese women to ensure that the same targets are to be achieved.

\section{R.2.9. We suggest against the use of routine ultrasound of the thyroid gland irrespective of thyroid function.}

\section{Reasoning:}

Autoimmune thyroiditis is often characterized by a hypoechogenic pattern on thyroid ultrasonography. Features of thyroiditis on ultrasound have the same predictive value as TPO antibodies for progression from subclinical to overt hypothyroidism in women (71). Generally, in the absence of additional clinical indications such as abnormal thyroid palpation, an ultrasound is not required neither in overt (20) nor in subclinical hypothyroidism (21). In addition, given the high frequency of thyroid nodules, up to $50 \%$ by the age of 60 years, systematic ultrasound examination of the thyroid can lead to unnecessary invasive and expensive acts (72). In addition to biochemical changes, structural changes of the thyroid have also been associated with obesity. These include increases in thyroid volume and hypoechogenicity as well as thyroid nodules $(27,73)$, which may be due to increased TSH stimulation or increase in inflammatory mediators produced by the adipose tissue (27). The improvement of thyroid hypoechogenicity after bariatric surgery argues for this hypothesis (74).

An increased incidence of thyroid cancers in patients with obesity or insulin resistance has been reported. A recent meta-analysis of 21 articles has shown a 55\% greater risk of thyroid cancer in patients with obesity. Each 5-unit increase in BMI was associated with 30\% greater risk of thyroid cancer and both general and abdominal adiposity increased the risk. Obesity was positively related to papillary, follicular and anaplastic thyroid cancers, but negatively with medullary thyroid cancer (75). The impact of obesity on thyroid cancer aggressiveness has still to be defined (76). Importantly, data showing that early detection of thyroid cancer by systematic ultrasound assessment improve the prognosis of thyroid cancer in patients with obesity are lacking. In conclusion, despite a greater incidence of morphological abnormalities and thyroid cancers in obesity, there is no sufficient data in the literature to recommend systematic ultrasound assessment in obesity.

\subsection{Testing for hypercortisolism}

R.3.1. We recommend that testing for hypercortisolism is not routinely applied in obesity $(++00)$.

\section{Reasoning:}

Obesity is commonly listed among the different entities of so-called pseudo-Cushing states $(77,78)$. When central obesity is present, accompanied by some specific signs and associated cardiovascular risk factors such as hypertension and/or type 2 diabetes, a diagnosis of Cushing's syndrome (CS) should be ruled out. The interest of unmasking endogenous hypercortisolism derives from its catabolic effects and devastating complications affecting quality of life and life expectancy unless properly treated (79). From a diagnostic perspective, difficulties arise to differentiate central obesity with associated comorbidities from mild CS. Despite a previous study has shown a prevalence of CS of $9.3 \%$ among a series of 150 patients with obesity (80), in most series the diagnosis of CS in obesity has been very uncommon, ranging from 0 to $0.7 \%$, though patients with severe obesity have been included $(81,82)$. In our review the pooled prevalence of CS in obesity was estimated $0.9 \%$ (95\% CI: 0.3-1.6) (16). On the other hand, a higher CS prevalence of $\sim 2-3 \%$ in patients with type 2 diabetes with poor metabolic control has been shown $(83,84,85)$. Moreover, subclinical CS has been reported to be more common in patients with obesity than in the general population (86), though its diagnostic criteria and treatment program have not been well established yet.

Assuming the epidemic proportions of obesity, its multifactorial origin and the low prevalence of CS among patients with obesity, the reported data do not lend support for a routine screening of CS in patients with obesity, according with previous recommendations (87). Therefore, screening for CS should be performed in patients who exhibit other specific features of hypercortisolism besides obesity.

\section{R.3.2. In patients with clinical suspicion of hypercortisolism biochemical testing should be performed $(++00)$.}

\section{Reasoning:}

Screening for CS diagnosis in patients with obesity, should be carried out in subjects who exhibit specific clinical features suggestive of hypercortisolism. In this context, catabolic signs such as skin atrophy, osteoporosis, spontaneous ecchymoses, proximal myopathy or wide purple striae increase the likelihood of CS $(77,78,88)$. The combination of some catabolic manifestations such as osteoporosis, spontaneous ecchymoses and thin skin is associated with a $95 \%$ probability of a diagnosis of CS (88). Other features such as central obesity, type 2 diabetes, hypertension or depression appear in CS but also are common in obesity (Table 4). These observations 
Table 4 Clinical features of hypercortisolism in obesity.

Wide purple striae
Easy bruising
Thin skin
Proximal myopathy
Osteoporosis
Dorsocervical fat pad
Facial plethora and
supraclavicular fullness
Peripheral oedema
Hyperandrogenism and/or
menstrual abnormalities
Erectile dysfunction, infertility
Truncal fat distribution (face,
neck, abdomen)
Type 2 diabetes
Hypertension and/or past history
of cardiovascular disease
Depression, insomnia, irritability,
cognitive impairment, psychosis
Incidental adrenal mass
Weight gain with growth
retardation (children)

\begin{tabular}{|c|c|}
\hline Obesity & Hypercortisolism \\
\hline No & Yes \\
\hline No & Yes \\
\hline No & Yes \\
\hline No & Yes \\
\hline No & Yes \\
\hline No & Yes \\
\hline No & Yes \\
\hline No & Yes \\
\hline $\begin{array}{l}\text { Often present in obesity associated } \\
\text { with polycystic ovarian syndrome }\end{array}$ & Yes \\
\hline $\begin{array}{l}\text { Often present in obesity without } \\
\text { associated hypercortisolism }\end{array}$ & Yes \\
\hline $\begin{array}{l}\text { Often present in obesity without } \\
\text { associated hypercortisolism }\end{array}$ & Yes \\
\hline $\begin{array}{l}\text { Often present in obesity without } \\
\text { associated hypercortisolism }\end{array}$ & Yes \\
\hline $\begin{array}{l}\text { Often present in obesity without } \\
\text { associated hypercortisolism }\end{array}$ & Yes \\
\hline $\begin{array}{l}\text { Often present in obesity without } \\
\text { associated hypercortisolism }\end{array}$ & Yes \\
\hline Often present in any patient & Not always \\
\hline No & Yes \\
\hline
\end{tabular}

\begin{tabular}{l} 
Mechanisms \\
\hline Catabolic effect \\
Catabolic effect \\
Catabolic effect \\
Catabolic effect \\
Catabolic effect \\
Fat redistribution \\
Fat redistribution \\
Increased fluid reabsorption \\
Gonadotrophin inhibition and \\
increased androgen secretion \\
Gonadotrophin inhibition \\
Fat redistribution \\
Hyperglycaemic effect \\
Increased circulating volume and \\
catecholamine sensitivity \\
Hypercortisolism effects on the brain \\
Potential origin of Cushing Syndrome \\
GH inhibition, effects on growth plates \\
and fat redistribution
\end{tabular}

underline the importance of clinical assessment to determine which patients should be screened for CS diagnosis. The presence of uncontrolled hypertension and/or type 2 diabetes despite conventional therapy in young patients with abdominal obesity may also raise the possibility of CS and justify the screening for detection of hypercortisolism (78). Other features that may increase the probability of CS are nephrolithiasis, frequent infections and hypokalaemia, though are less specific than catabolic manifestations (Table 4).

\section{R.3.3. We recommend that in patients going for bariatric surgery (testing for) hypercortisolism should be considered.}

\section{Reasoning:}

Candidates to bariatric surgery commonly present with obesity-related comorbidities such as hypertension, metabolic syndrome and type 2 diabetes, which are also frequent in CS. Despite CS being a very rare disease, eventually some candidates to bariatric surgery may have endogenous hypercortisolism that could lead to severe adverse effects after surgery if undiagnosed (89). Factors such as hypercoagulability, catabolic state and increased cardiovascular risk may be responsible for severe postoperative complications, making this scenario especially sensible for CS detection (90).

Although the prevalence of CS in patients with severe obesity is generally low $(81,82,91)$, a study of 16 patients operated of bariatric surgery has shown that CS diagnosis, persistence or recurrence was unrecognised, suggesting that CS may be responsible for less than expected improvement in hypertension and diabetes control as well as intense weight regain after bariatric surgery (92). Therefore, particular attention should be paid to patients who are candidates to bariatric surgery to rule out a diagnosis of CS, especially if suspicious clinical features are present (Table 4). Although biochemical preoperative screening for CS in all severe obesity patients is controversial (93), in candidates to bariatric surgery special attention to rule out CS in patients with suspicious clinical signs is needed to prevent potential surgical complications or adverse clinical outcomes following surgery.

\section{R.3.4. We suggest that for patients with obesity the same normal values are applied as for non-obese (+000).}

\section{Reasoning:}

Some experimental and clinical data points to a dysregulation in the activity of HPA axis in some patients with abdominal obesity, including excessive cortisol response to physical and psychological stimuli, reduced glucocorticoid feedback sensitivity and increased activity of 11-beta hydroxysteroid dehydrogenase in adipose tissue (94). However, other factors such as chronic stress may also be involved and hair cortisol measurement, 
when available, may offer a better reflection of chronic cortisol exposure than plasma or salivary samples (95).

Most studies rely on $1 \mathrm{mg}$ late-night dexamethasone suppression as the screening method to detect CS in obesity. Despite that subjects with abdominal obesity may display less cortisol suppression in some cases, the vast majority of authors consider that this test shows an acceptable performance to rule out CS $(78,87,95)$. Special attention should be paid to the simultaneous use of drugs that may disturb dexamethasone metabolism leading to potential false results (78). Although some studies have tested different cut-off points for cortisol suppression and diverse dexamethasone doses, there is no solid evidence to use different methodology or interpretation criteria from those considered in normal body weight. Likewise, there are no reasons to consider different cut-offs to evaluate nocturnal salivary cortisol or other functional HPA function parameters in patients with obesity.

\section{R.3.5. We recommend not to test for} hypercortisolism in patients using corticosteroids.

\section{Reasoning:}

Exogenous corticosteroid therapy interferes with HPA axis assessment, by inducing cushingoid clinical features and suppressed endogenous HPA axis activity. Guidelines recommend investigating whether patients are on glucocorticoid treatment before starting evaluation for potential endogenous CS $(78,87,95)$. In cases of exogenous corticosteroid therapy, the main interest is usually focussed on the impairment or recovery of HPA function rather than on the diagnostic possibility of endogenous CS.

\section{R.3.6. If hypercortisolism testing is considered, we recommend a $1 \mathrm{mg}$ overnight dexamethasone suppression test as first screening tool.}

\section{Reasoning:}

A $1 \mathrm{mg}$ overnight dexamethasone suppression test is simple, well standardized and used in the majority of previous studies (79). The risk of false-positive tests in severely obese patients is increased, but the specificity is still relatively high even in patients with severe obesity (92\% in a recent study) (81). This test is sufficiently sensitive to rule out hypercortisolism with the threshold of post dexamethasone levels $\leq 50 \mathrm{nmol} / \mathrm{L}(\leq 1.8 \mu \mathrm{g} / \mathrm{dL})$ or equivalent method-dependent cut-off value (96). A recent study did not find significant advantage of using $2 \mathrm{mg}$ vs $1 \mathrm{mg}$ suppression test in patients with obesity (97). In line, a study has shown that adjustment of the dexamethasone dose to body weight does not seem to substantially improve the sensitivity of the test, even in individuals with obesity, particularly when near-maximal doses are administered. In addition, an effect of sex on post-dexamethasone cortisol concentrations, suppression of the HPA axis, and dexamethasone levels has been found, which may be dependent on differences in both cortisol and dexamethasone metabolism. On the other hand, at least in women, abdominal fat distribution may partially counteract the progressively greater suppressibility of the HPA axis that would be expected according to increasing BMI (98).

R.3.7. If the $1 \mathrm{mg}$ overnight dexamethasone suppression test is positive, we recommend a second biochemical test; this can be either 24-h urine cortisol or late-night salivary cortisol.

\section{Reasoning:}

The positivity of $1 \mathrm{mg}$ overnight dexamethasone suppression test can be influenced by the presence of other comorbidities such as depression (99), alcoholism (100) and obstructive sleep apnoea (101) that are common in patients with obesity. Therefore, additional biochemical tests are needed in particular in patients with borderline cortisol post dexamethasone levels (between 51 and 138 $\mathrm{nmol} / \mathrm{L}(1.9-5.0 \mu \mathrm{g} / \mathrm{dL}$ ) (see ESE guideline management of adrenal incidentaloma for further information (96)). Confirmation of endogenous hypercortisolism requires the combination of different tests of adrenal function as recommended by the Endocrine Society guidelines (78). We suggest that after a $1 \mathrm{mg}$ overnight dexamethasone suppression test, urinary-free cortisol (UFC) or/and latenight salivary cortisol are measured to establish or rule out the diagnosis of endogenous hypercortisolism. Mind that urinary-free cortisol values are inconsistently elevated in patients with obesity (94), though some studies have shown a relationship between BMI and waist circumference and UFC (102).

R.3.8. In all patients with confirmed hypercortisolism, an ACTH should be measured and further imaging should be performed to find the cause/source of the hypercortisolism.

\section{Reasoning:}

ACTH measurements, which are not altered by obesity (103), should be performed to investigate the cause of hypercortisolism. These further measurements and examinations will help to establish the exact causes of hypercortisolism and guide the therapeutic approach. In cases of ACTH-independent hypercortisolism the appropriate imaging methods (non-contrast CT as primary choice) are necessary to distinguish between benign or potentially malignant type of adrenal mass 
(104). When normal or high ACTH values are detected in patients with confirmed hypercortisolism pituitary MR and in some cases inferior petrosal sinus sampling should be performed to differentiate Cushing's disease of pituitary vs ectopic origin (78).

\section{R.3.9. Treatment of proven endogenous hypercorti- solism is not normalizing BMI in most cases.}

\section{Reasoning:}

In case of confirmed hypercortisolism, treatment of hypercortisolism has the highest priority. Although endogenous hypercortisolism contributes to weight gain, its treatment (surgical or conservative) does not lead to normalization of BMI in the majority of patients $(105,106)$. These findings suggest that endogenous hypercortisolism is in most of the patients a contributing factor rather than a sole cause of obesity.

\subsection{Testing for hypogonadism in males}

R.4.1. We recommend that biochemical testing for hypogonadism is not routinely applied in male obese patients; we do recommend investigating key clinical symptoms/signs of hypogonadism (++00).

\section{Reasoning:}

Male obesity-secondary hypogonadism (low plasma testosterone concentrations) has been reported in up to $45 \%$ of patients with moderate-to-severe obesity (107); in our review, we found a pooled prevalence of hypogonadism based on free testosterone measurements of $32.7 \%$ (95\% CI: 23.1-43.0) (16). Moreover, obesity impairs sperm concentration, motility and morphology (108). Patients with obesity and associated comorbidities such as metabolic syndrome or type 2 diabetes exhibit a higher prevalence of hypogonadism (109). In fact, 75\% of patients with class III obesity waiting for bariatric surgery have hypogonadism on the basis of a testosterone value lower than $12.1 \mathrm{nM} / \mathrm{L}$ (110). Accordingly, severe obesity is listed as a cause of functional secondary hypogonadism (111). Other terms such as late-onset hypogonadism and dysmetabolic hypogonadotrophic hypogonadism may also apply to this condition reflecting the participation of several metabolic factors such as obesity, visceral fat excess, insulin resistance, inflammation, oxidative stress and type 2 diabetes in its pathophysiology $(107,108,111,112,113,114$, 115). There are multilateral relationships between obesity, hypogonadism, type 2 diabetes and metabolic syndrome. Thus, obesity-associated comorbidities are commonly accompanied by low testosterone values and, on the other hand, low testosterone plasma values are associated with obesity, metabolic syndrome and type 2 diabetes (116). The increase in aromatase activity in adipose tissue, responsible for converting testosterone into oestradiol, may also contribute to inhibit LH secretion and reduce testosterone (117), as well as oestradiol blood levels (109). A dysregulation of the hypothalamic-pituitary-adrenal axis inducing functional hypercortisolism in obesity may also play a role in gonadotrophin inhibition and, consequently, reduced testosterone levels (94). As for the general population (111), a routine hormonal screening for male hypogonadism is not recommended in patients with obesity, and testing should be considered when clinical features create the need for investigating hypogonadism (Table 5). Therefore, we recommend investigating routinely key clinical symptoms/signs of hypogonadism in all men with obesity, including proper testicular size assessment. In line, we suggest that obese patients with metabolic syndrome and/or insulin resistance and/or type 2 diabetes are tested for the presence of hypogonadism especially if the clinical picture is suspicious of hypogonadism $(113,118)$.

R.4.2. In male patients with obesity with clinical features of hypogonadism we suggest measuring total and free testosterone (or calculated), SHBG, FSH and LH.

\section{Reasoning:}

Once clinical suspicion has been established, total testosterone plasma concentrations represent the initial

Table 5 Clinical symptoms/signs of male hypogonadism.

Erectile dysfunction*

Weakness of morning erections*

Reduced sexual desire*

Reduction in lean body mass

Muscle weakness*

Gynoid fat distribution*

Hot flushes*

Osteoporosis*

Infertility*

Changes in mood, fatigue*

Cognitive impairment

Sleep disturbances*

Decreased androgenic body hair

Gynaecomastia and reduced testicular volume

Other symptoms/signs of anterior pituitary dysfunction

*Indicate some non-specific symptoms that are relevant for male obesity-secondary hypogonadism diagnosis. 
tool for investigating hypogonadism (111). Since there is a circadian rhythm of testosterone secretion, the sample should be taken in the morning between 0700 and 1100 $\mathrm{h}$ or within $3 \mathrm{~h}$ after waking-up in case of shift workers (119). On the other hand, daily circadian rhythm and pulsatile LH and testosterone pattern tend to flatten with increasing age (120). Low testosterone concentrations should be confirmed by taking morning samples in two separate days in fasting state, since food intake suppresses testosterone levels $(111,119)$. It is recommended to measure free testosterone levels when total testosterone is found to be near the lower limit of the normal range (111). In those situations, SHBG and free testosterone concentrations determine biochemical basis for the diagnosis of male hypogonadism $(121,122)$.

However, since the gold standard procedure to measure free testosterone (equilibrium dialysis) is not widely available, it may be preferable to calculate bioavailable testosterone by using testosterone, sex hormonebinding globulin (SHBG) and albumin concentrations $(111,123)$. This suggestion applies especially to obesity, since body fat excess and insulin resistance are commonly associated with low SHBG circulating values $(111,116)$, complicating the interpretation of testosterone concentrations. In general, a combination of low testosterone levels with clinical features of hypogonadism such as decreased sexual thoughts, erectile dysfunction and reduced morning erections is required for a formal male obesity-secondary hypogonadism diagnosis (117).

Once low testosterone concentrations have been demonstrated, FSH and LH measurements are useful to distinguish between primary and secondary hypogonadism (111). Male obesity-secondary hypogonadism is associated with low plasma gonadotrophin concentrations, and in some cases with predominance of FSH over LH (107), in contrast with primary hypogonadism, where gonadotrophins are elevated. Once hypogonadotrophic hypogonadism has been diagnosed, other causes of secondary hypogonadism should be excluded before attributing the hormonal disorder to obesity; especially hyperprolactinaemia, leptin signaling abnormalities, syndromic or hypothalamic obesity are frequently associated with hypogonadotrophic hypogonadism (111). When secondary hypogonadism has been confirmed biochemically, morphological exploration of the hypothalamic-pituitary region by MRI may also be needed in selected patients (111). If imaging exploration is negative leptin assessment and genetic evaluation have to be considered.

\section{R.4.3. In obesity we suggest applying age specific reference ranges for testosterone $(+000)$.}

\section{Reasoning:}

Male testosterone levels decrease with age, though recent reports suggest that the magnitude of testosterone reduction seems to be lower than previously thought (124, 125). Nevertheless, these studies are based on single morning samples, disregarding pulsatile, diurnal and circannual testosterone rhythms. Although obesity is associated with an increased prevalence of hypogonadism, no adjustments for BMI are used to confirm the biochemical diagnosis of hypogonadism (107). Moreover, testosterone measurements are affected by chronic diseases, medications, genetics, lifestyle, and intra-individual variations (126). All these aspects should be considered when interpreting a testosterone result.

Testosterone results also depend on the assay technique used. Most available testosterone assays are immunoassays (RIA, enzyme immunoassay or fluoroimmunoassay), which are rapid, simple and inexpensive. Moreover, most reference ranges have been established using immunoassays. However, their accuracy is lower than that obtained by mass spectrometry, which is more expensive and requires regular calibration. Nevertheless, liquid chromatography tandem mass spectrometry (LC-MS) has become progressively adopted showing better precision $(118,125,126)$. Variability between immunoassays and LC-MS ranges from -14 to $+19 \%$, (127). Preparation and handling of the sample as well as calibration also have an impact on variability (126).

Equilibrium dialysis represents the gold standard method to measure free testosterone but is expensive and technically challenging. For practical reasons, most guidelines recommend direct measurements or calculation of free testosterone by a formula. Correlation with measurements performed with equilibrium dialysis is good, but results depend on dissociation constants for binding of SHBG and albumin and on the accuracy of assays used (see for review (126)).

Regarding normal reference ranges for testosterone, the Endocrine Society proposes $9.2-31.8 \mathrm{nmol} / \mathrm{L}$ in healthy men aged 19-39 years (125), whereas the Endocrine Society of Australia considers a range of 10.4-30.1 nmol/L for men aged 21-35 years and 6.4-25.7 nmol/L for men aged 70-89 years measured by mass-spectrometry without specific reference to obese people (128). The European Male Aging Study has suggested a cut-off value of total testosterone of $11 \mathrm{nmol} / \mathrm{L}(3.2 \mathrm{ng} / \mathrm{mL})$ to define hypogonadism associated to the presence of three sexual symptoms (118), which 
is probably applicable for the general male European population including patients with obesity.

\section{R.4.4. We recommend emphasizing the impor- tance of weight loss to restore eugonadism in obese patients with biochemical and clinical hypogonadism.}

\section{Reasoning:}

There is compelling evidence highlighting the potential of a vicious cycle where obesity can lead to functional male hypogonadism, while male hypogonadism can further promote adiposity. Indeed, increased fat mass and reduced fat free mass is a common feature among men with androgen deficiency (129), although rarely having a significant impact on BMI (130).

Weight loss should be the first-line therapeutic approach aiming to reverse functional male hypogonadism in obesity. However, health care practitioners must be aware that conservative interventions with lifestyle modification, diet and exercise, achieving 5\% weight loss may be insufficient to normalize testosterone levels (131). Besides, the ability to sustain the male gonadal benefits after weight loss achieved through conservative interventions is relatively small, as weight regain is also very common. Given the limited evidence for benefits along with the potential risks, testosterone therapy along with lifestyle interventions is not recommended in patients with functional male hypogonadism $(132,133)$.

In severely obese patients, bariatric surgery is a very effective means of increasing testosterone levels and recovery of the hypothalamic-pituitary gonadal axis function besides achieving significant and sustained weight loss $(134,135)$. In addition, hypogonadal men with obesity submitted to bariatric surgery are reported to lose more weight than eugonadal men (136). However, despite the improvement in gonadal function, this is no warranty that sperm characteristics will also improve $(137,138)$.

R.4.5. We suggest that if weight loss cannot be achieved and if clinical and biochemical hypogonadism persists, treatment with testosterone can be considered in individual cases; contra-indications should be considered and other causes of hypogonadism should have been ruled out. The sole presence of obesity is not enough reason to start testosterone $(+000)$.

\section{Reasoning:}

In case weight loss is not achieved and/or if testosterone levels and symptoms/signs of hypogonadism do not improve and other causes of hypogonadism have been excluded, testosterone replacement therapy (TRT) can be considered on an individual basis, considering potential benefits, side effects and risks. In that case, TRT should be added to lifestyle intervention oriented to weight loss. It is advisable to take this decision in the context of a multidisciplinary medical team, and patients should be well informed on potential benefits and adverse effects. Potential side effects of TRT include erythrocytosis, growth of prostate or breast cancer $(111,116)$. The injectable preparation of testosterone undecanoate (1000 mg every 12 weeks) is widely used as treatment of hypogonadism because it leads to steady testosterone plasma levels. Disadvantages are related to its large volume of injection that can induce pain at the injection site, rare cases of cough following the injection and due to its long duration of action in case of intolerance, since the effects will be maintained for 3 months. Transdermal testosterone application is also associated with stable circulating levels, but can induce skin irritation and can transfer hormonal effects to other persons by physical contact with the applied drug $(111,116)$.

Table 6 depicts contraindications for TRT (139). An association between TRT and sleep apnoea has been reported (140); the exact relationship between TRT and prostate cancer development is not well established. Nevertheless, given the stimulatory effect of testosterone on growth of metastatic prostate cancer, prostate cancer is considered as a contraindication for testosterone therapy (111). High haematocrit, breast cancer, severe sleep apnoea, heart failure and urinary tract symptoms also represent contraindications for testosterone administration $(111,141)$.

Although TRT given to men with hypogonadism is associated with weight loss and body composition improvement, no evidence of this beneficial effect is observed in eugonadal subjects. Therefore, TRT is not indicated for men with obesity and normal hypothalamic-pituitary gonadal function.

Table 6 Contraindications for testosterone therapy.

Haematocrit $>54 \%$

Prostate cancer

Male breast cancer

Active desire to achieve fertility

Severe sleep apnoea

Severe lower urinary tract symptoms due to prostatic enlargement

Severe cardiac failure 
R.4.6. We suggest treatment with testosterone aiming at testosterone levels in the normal range $(+000)$.

\section{Reasoning:}

The main aim of TRT is to reverse the symptoms and signs attributed to testosterone deficiency (Table 5). Although there are no sufficient data to establish the testosterone concentration that should be achieved, the objective is to restore testosterone values to the mid-normal range of a specific age. Haematocrit, prostate health status and the cardiovascular situation should be evaluated regularly after starting TRT to monitor potential side effects.

\section{R.4.7. We suggest stopping testosterone treatment if clinical features are not improving despite biochemical restoration for 6-12 months (+000).}

\section{Reasoning:}

All symptoms/signs of hypogonadism should be re-evaluated regularly to monitor the efficacy of TRT $(111,116)$. TRT may be associated with diverse side effects such as erythrocytosis (haematocrit higher than 54\%), androgenic manifestations such as acne and male pattern balding, prostatic growth, reduced sperm production, worsening of sleep apnoea, gynaecomastia, and growth of breast cancer (111). Appearance of these signs may lead to reduction of testosterone dose or termination of treatment.

The effects of TRT on sexual desire are usually evident after 3 weeks of treatment, whereas the improvement in mood may be evident from the first month of therapy. Erectile dysfunction may require 6 months of treatment to recover (139). Following TRT, a reduction in fat mass and an increase in lean body mass are expected as well as improvements in insulin resistance, lipid profile and BMI (142). In case that TRT is not associated with an improvement of the symptoms/signs of hypogonadism after 6-12 months of treatment, stopping testosterone should be considered to prevent potential side effects.

R.4.8. We do not recommend testosterone treatment as a first therapeutic measure in hypogonadal male patients with obesity seeking fertility (+000).

\section{Reasoning:}

Testosterone administration is followed by inhibition of gonadotrophin secretion and suppression of spermatogenesis and, therefore, is contraindicated as monotherapy when males with hypogonadotrophic hypogonadism desire fertility over the next year
$(111,143)$. In those men seeking to conceive, additional care must be taken, since testosterone treatment may halt spermatogenesis. Therefore treatment with gonadotropins should be the first-line therapy, in order to ensure or recover spermatogenesis (143).

\subsection{Testing for gonadal dysfunction in females}

R.5.1. We recommend that testing for gonadal dysfunction is not routinely applied in female patients with obesity $(++00)$.

\section{Reasoning:}

Routine testing for gonadal dysfunction in female obese patients is not recommended unless there is relevant clinical suspicion, such as menstrual abnormalities, infertility or symptoms/signs of hyperandrogenism. Nevertheless, it should be noticed that polycystic ovary syndrome (PCOS) occurs in 29\% of female patients with obesity (144) reaching up to $36 \%$ of women with severe obesity (145). Obesity in females can be associated with relative functional hyperandrogenism $(146,147)$; women should undergo further evaluation when suggestive symptoms or signs such as acne, hirsutism, or androgenic alopecia are present. In fact, obesity plays a major role in determining female hyperandrogenaemia, especially in adolescence in what has been defined as obesity-related hyperandrogenaemia $(146,148)$. Although the precise mechanisms remain unclear, these are likely related to the effects of insulin on steroidogenic cells that retain insulin sensitivity $(146,148)$. In addition, infertility and a medical history of recurrent miscarriages can also be clinical manifestations of obesity-related gonadal dysfunction (149). From a perspective of diagnostic characterization, the presence of PCOS is established according to the Rotterdam consensus, which requires the presence of two out of three criteria including hyperandrogenism, chronic anovulation and polycystic ovaries as assessed by ultrasound (150).

Particularly when accompanied with visceral fat excess, PCOS is frequently associated with insulin resistance and metabolic sequelae, such as type 2 diabetes, dyslipidaemia and cardiovascular risk factors that can affect women across the lifespan (151). In this context, measurement of fasting glucose and insulin plasma concentrations should be carried out in obese women with PCOS in order to confirm insulin resistance and take action to prevent the metabolic consequences (17). Thus, visceral obesity, insulin resistance and hyperandrogenism show multilateral relationships that justify the interest 
to be assessed in the context of obesity-induced gonadal dysfunction in patients with suggestive clinical features.

\section{R.5.2. We suggest to assess gonadal function in female patients with obesity with menstrual irregularities and chronic anovulation/infertility.}

\section{Reasoning:}

Obesity is associated with fertility impairment and increased risk of miscarriages, even in the absence of a formal diagnosis of PCOS (149). Diverse pathological factors may mediate these phenomena, which include insulin resistance and low-grade inflammation (149). The presence of irregular periods, infertility should be further investigated with adequate endocrine tests aiming to confirm or exclude hyperandrogenaemia, anovulation, PCOS and insulin resistance, as well as other secondary causes of female gonadal dysfunction. In case of androgen excess other clinical entities apart from PCOS should be excluded, such as congenital adrenal hyperplasia, severe insulin resistance, adrenal disorders and iatrogenic factors. In the presence of menstrual disorders or infertility, the endocrine evaluation should also include assessment of hyperprolactinaemia, thyroid dysfunction and hypercortisolism, which can be responsible for additional specific clinical features.

R.5.3. For evaluation of menstrual irregularity we suggest to assess gonadal function by measuring LH, FSH, total testosterone, SHBG, $\Delta$ 4androstenedione, oestradiol, 17-hydroxyprogesterone and prolactin. If the menstrual cycle is irregular but somewhat predictable, we suggest that the assessment should take place during the early follicular phase.

\section{Reasoning:}

For evaluation of menstrual irregularity, we suggest gonadal function to be assessed by measuring circulating levels of $\mathrm{LH}, \mathrm{FSH}$, total testosterone, SHBG, $\Delta 4$ androstenedione, oestradiol, 17-hydroxyprogesterone and prolactin. These measurements are primarily aimed to establish or exclude PCOS, since obesity is commonly associated with clinical and biochemical characteristics of this syndrome (152, 153). This biochemical profile should also be investigated in symptomatic adolescent women with obesity. Although less common, since patients with late-onset congenital adrenal hyperplasia may present clinical features similar to PCOS, plasma 17-hydroxyprogesterone should also be included to rule out 21-hydroxylase deficiency (154). We recommend hormonal assessments to be preferably performed in the early follicular phase of the menstrual cycle (1st to 5th day of the menstrual cycle), when most reference values have been established. In the presence of amenorrhoea and unpredictable menstrual cycles, these hormonal assessments can be performed at any time.

We suggest that gynaecological assessment, including ovarian ultrasound scan (US) evaluation should be considered to define polycystic ovarian morphology (PCOm) in order to enable PCOS diagnosis by applying the established Rotterdam Criteria (155).

R.5.4. For evaluation of anovulation we suggest gonadal function to be assessed by measuring LH, FSH, oestradiol, progesterone and prolactin.

\section{Reasoning:}

These hormone measurements should help to distinguish between primary ovarian failure and central hypogonadism. Although obesity-associated gonadal dysfunction is due to hypothalamic dysfunction, patients with primary ovarian failure may also develop obesity. In primary hypogonadism, high levels of FSH and LH are found in contrast with central hypogonadism, where low gonadotrophin values arise. Special attention should be paid to FSH, which is differentially high in primary ovarian failure, whereas it is low in a typical PCOS presentation as well as in central hypogonadism. In contrast, high LH values are characteristic of primary hypogonadism, but may also be present in some patients with PCOS as a consequence of hypothalamic-pituitary dysfunction, either primary or induced by peripheral androgen imbalance $(153,155)$.

Hyperprolactinaemia is a recognized cause of anovulation and infertility. Therefore, prolactin plasma concentrations should be measured and the potential causes for hyperprolactinaemia should be further investigated. When ovulation assessment is the objective, measurement of progesterone in the mid-luteal phase of the menstrual cycle should also be performed (153).

When hormonal evaluation is compatible with central hypogonadism, a possible global impairment of hypothalamic-pituitary function affecting other hormonal axis should be investigated and imaging of the hypothalamic-pituitary region may be needed to rule out tumours; other functional disturbances potentially leading to biochemical central hypogonadism are chronic stress, eating disorders or severe chronic systemic diseases.

R.5.5. We recommend to assess androgen excess when PCOS is considered based on the clinical features. We suggest to measure total 
testosterone, free $T, \Delta$ 4androstenedione and SHBG. We additionally recommend to assess ovarian morphology and blood glucose.

\section{Reasoning:}

Clinical features that raise PCOS suspicion include acne, hirsutism, androgenic alopecia, acanthosis nigricans, menstrual abnormalities, oligo-anovulation, infertility and obesity. If there is clinical suspicion of PCOS, hyperandrogenism (either clinical or hormonal), anovulation and ultrasonographic features of polycystic ovaries (PCOm) need to be investigated, in order to confirm the diagnosis of PCOS according with Rotterdam criteria. Androgen plasma levels including total testosterone, free testosterone (if measured by equilibrium dialysis), SHBG, $\Delta$ 4androstenedione should be measured to confirm biochemical hyperandrogenaemia $(152,156)$. An estimation of free testosterone can be carried out by using formulas based on plasma concentrations of total testosterone, SHBG and albumin (123), see for details 5.4.3. Ovarian ultrasonography, assessed by an experienced gynaecologist/ radiologist, is needed to confirm whether Rotterdam criteria are present supporting the diagnosis of PCOS (155).

PCOS is frequently associated with insulin resistance and increased risk for type 2 diabetes. Fasting glucose values should be measured and the AE-PCOS Society recommends to perform an oral glucose tolerance test in obese patients and in those patients with risk factors for type 2 diabetes (157). Additionally, fasting insulin measurement gives the opportunity to calculate the HOMA-IR index to evaluate insulin resistance. HbA1c measurement may be useful to characterize glucose tolerance status. Whether PCOS is associated with an increased cardiovascular risk is still under debate, nonetheless special attention should be paid to the possible presence of metabolic syndrome in these patients $(153,155)$.

\section{R.5.6. We suggest to initiate metformin treatment in women with PCOS that additionally present metabolic syndrome features $(++00)$.}

\section{Reasoning:}

Metformin is commonly used for managing insulin resistance in patients with PCOS. Metformin acts by increasing insulin sensitivity predominantly in liver, muscle and adipose tissue, thus improving cardiometabolic risk factors, menstrual abnormalities and fertility. Provided that insulin resistance plays a role in PCOSrelated hyperandrogenaemia and hypothalamic-pituitary ovarian dysfunction, metformin can be a therapeutic approach to enable restoration of hormone imbalance in patients with obesity and gonadal dysfunction, with the additional benefit of improving the patient's metabolic profile. Therefore, in addition to lifestyle intervention, metformin represents a preferential option to treat patients with PCOS exhibiting insulin resistance (153).

R.5.7. We recommend not to start metformin with the sole aim to reduce body weight (+000).

\section{Reasoning:}

Although metformin may induce mild appetite and body weight reduction, it cannot be considered as a drug for obesity treatment. Accordingly, we recommend against using metformin with the sole aim of promoting weight loss. Other medications, such as liraglutide or orlistat, are available for obesity treatment as adjuvants to lifestyle interventions and can be used to promote weight loss (158).

R.5.8. We recommend not to start oestrogen substitution in postmenopausal obese women with the sole aim to reduce body weight $(+000)$

\section{Reasoning:}

Oral contraceptives can be used to reduce androgen blood levels in women with PCOS (159). However, despite most formulations containing low doses of oestrogens and although very rare, a potential risk of venous thromboembolism does exist (160). Oestrogen treatment is not recommended in postmenopausal obese women with the sole aim to reduce body weight (161). The potential negative impact on metabolic issues and cancer is questionable.

\subsection{Other hormones}

R.6.1. We recommend that testing for IGF1/GH is not routinely applied in obesity $(+000)$.

R.6.2. We suggest testing for IGF1/GH only in patients with suspected hypopituitarism; if tested a dynamic test should be performed as a minimum (+000).

R.6.3. We recommend not to use GH to treat obesity in patients with normal GH levels (+000).

\section{Reasoning:}

Growth hormone $(\mathrm{GH})$ secretion is pulsatile with strong 24-h variations, then basal GH levels are not useful for evaluating the somatotrope axis. That requires the use of stimulation tests, i.e. administering factors that elicit a GH discharge, such as GHRH, arginine or insulin-induced 
hypoglycaemia. The interest for GH in obesity arose after the observation that stimulated GH secretion is blocked in adults and children with excess of weight (162). Moreover, such a blockade vanishes when the patient loses weight or returns to normal weight $(162,163)$. These observations led some scientists to debate whether obesity per se is a state of true GH deficiency. The conclusion was negative, based in the following data: (a) basal GH levels are in general low but mostly similar to that of non-obese normal subjects of similar age (164), (b) IGF-I levels are normal in obesity (165), (c) only few of the signs and symptoms of adult GH deficiency is present in adult obese subjects, and (d) obese children with such absent GH secretion have a normal growth, or even, sometimes greater than that observed in non-obese children. Slight reduction in IGF-I levels are observed in patients with severe obesity, but complete recovery was observed after weight loss achieved by bariatric surgery (166).

Although true GH deficiency tends to modestly increase adipose tissue and decrease muscle mass, and these minor effects are reversible after GH replacement, obesity cannot be attributed to GH deficiency per se nor is GH deficiency a major contributor for obesity (167, 168). For all of the above, neither basal IGF-I nor basal or stimulated GH should be measured when evaluating obese patients, nor should GH treatment be considered an option for the treatment of obesity.

\section{R.6.4. We suggest not to perform routine tests for vitamin $D$ deficiency in patients with obesity (+000).}

\section{Reasoning:}

Vitamin D deficiency defined based on the presence of low serum 25-hydroxyvitamin D (25OHD) levels is very frequent in obesity and was reported to occur in 55-97\% $(169,170)$. However, it is important to understand the mechanisms underlying the lower 25OHD levels in obesity and whether this indicates a clinically significant vitamin D deficiency. Vitamin D is a fat-soluble vitamin, so the lower 25OHD levels in obese individuals can be attributed to a volumetric dilution effect, while vitamin D stores can be adequate. In addition to decreased vitamin D bioavailability due to body fat sequestration, other obesity-related factors may also contribute for a true vitamin $\mathrm{D}$ deficiency such as malnutrition with a low vitamin D intake, sun avoidance and lower skin synthesis (171). Patients with obesity also need higher loading doses of vitamin $\mathrm{D}$ to achieve the same serum 25-hydroxyvitamin D (172). Therefore, low 25OHD levels may not always reflect a clinical problem.
The relationship of vitamin D deficiency with obesity, diabetes, insulin resistance, and metabolic syndrome has been considered likely based of the fact that vitamin $\mathrm{D}$ receptors and the 1-alpha hydroxylase enzyme are distributed ubiquitously in all tissues suggesting a multitude of functions of vitamin D, while vitamin D plays an indirect but an important role in carbohydrate and lipid metabolism (173). In the past two decades, numerous observational studies suggested vitamin D deficiency was a risk factor for obesity, T2D, insulin resistance and metabolic syndrome, while hypothesising that re-establishing vitamin D adequacy could lead to the improvement of these conditions. However, there is a lack of conclusive evidence from randomized control clinical trials to support that optimization of 25OHD levels is able to prevent these metabolic disorders (174), has beneficial effects on glucose homeostasis (175) or results in a lower incidence of cardiovascular events (176). Therefore, vitamin D supplementation with the sole purpose of promoting weight loss, decreasing the risk of obesityrelated co-morbidities or improve ongoing metabolic conditions cannot be recommended.

R.6.5. We suggest not to test for hyperparathyroidism routinely in patients with obesity $(+000)$.

\section{Reasoning:}

Vitamin D is essential for bone-mineral health and calcium homeostasis. Vitamin D deficiency elicits a compensatory rise in parathyroid hormone (PTH), which increases bone turnover and calcium mobilization from the skeleton, leading to a decrease in bone mineral density and increase in the risk of osteopenia and osteoporosis (177). Thus, vitamin D deficiency to the extent that will drive an increase in bone turnover or decrease bone mineral density is clinically relevant. The prevalence of secondary hyperparathyroidism (sHPT) related to vitamin D deficiency in obesity was reported to be over $20 \%(169,178)$ and increased up to $71 \%$ depending on vitamin D status (171), while the threshold for parathyroid stimulation can be widely variable $(179,180)$. In addition to disturbances in the vitamin D - calcium homeostasis, obesity may involve other mechanisms affecting PTH regulation that are incompletely understood. For an instance, obesity is associated with reductions in total and free 25OHD but unchanged vitamin-D binding proteins, which are among the most polymorphic proteins known and different alleles can have substantial impact on its biologic functions $(181,182)$. Therefore, the etiology of sHPT in obesity is not well established. 
Notwithstanding, PTH levels should not be routinely assessed in obese patients, unless in the presence of signs which lead to the clinical suspicion of hyperparathyroidism, such as hypercalcaemia, osteoporosis and nephrolithiasis.

Still, it should be noticed that an exception for routine measurement of 25OHD and PTH should be made for patients with obesity submitted to bariatric procedures. The prevalence of sHPT was observed to increase up to $50 \%$ in patients 2 years after bariatric surgical interventions. In addition, in order to prevent or attenuate bone loss it is recommended to ensure that sufficient 25OHD levels are attained (171), bearing in mind that vitamin D supplements in higher dosages are required to overcome decreased absorption (183). However, the ideal vitamin D replacement therapy and target $25 \mathrm{OHD}$ concentrations in the obese or bariatric populations are unknown. Moreover, whether vitamin D supplementation actually protects against weight loss induced bone loss and fractures still needs to be confirmed (184).

\section{R.6.6. We recommend not to test routinely other hormones, such as leptin and ghrelin, unless there is suspicion of a syndromic obesity.}

\section{Reasoning:}

Serum leptin concentration is increased in patients with simple obesity and correlates with BMI and body fat content (185). Measurements of serum leptin levels should only be considered in severe early-onset obesity to rule-out missense leptin gene mutations (186). These mutations are extremely rare and lead to undetectable circulating leptin levels (187). Typical features suggestive of missense leptin gene mutations are normal birth weight with rapid weight gain in the first months after delivery leading to severe obesity (mean BMI SDS: 5.8-7.8) along with extreme hyperphagia (food intake 3-5-fold higher compared to healthy children), and T-cell number and function abnormalities with higher rates of infections (188). Patients with leptin receptor gene mutations have a similar phenotype to leptin gene mutation patients but their serum leptin concentrations are usually appropriate for the degree of obesity (189). Both leptin- and leptinreceptor gene mutations are associated with hypothalamic hypothyroidism (low FT4 and TSH levels), growth hormone deficiency (in some patients) and lack of normal pubertal development (in majority of patients) $(186,187,189)$.

Circulating ghrelin levels are decreased in patients with obesity compared to normal subjects and they tend to normalize in patients able to recover ideal body weight (190). Bariatric surgery in particular the operations that include resection of gastric fundus decrease ghrelin levels while diet-induced weight loss usually increases ghrelin concentration (191). The only specific obesity syndrome where increased ghrelin levels were described and could potentially contribute to weight gain are patients with Prader-Willi syndrome (192). These patients typically present with significant weight gain in childhood, significantly increased appetite, GH deficiency, hypogonadism, sleep disturbances and other abnormalities. The diagnosis of this syndrome can be established based on clinical features, hormonal abnormalities and genetic testing. Therefore, measuring ghrelin levels in Prader-Willi patients has little additional diagnostic value and should not be done in routine clinical settings.

\section{R.6.7. We suggest to consider secondary causes of hypertension in the context of therapy-resistant hypertension in obesity.}

\section{Reasoning:}

There are some endocrine disorders associated with both hypertension and obesity (193) where testing for secondary endocrine hypertension should be considered. These include in particular primary aldosteronism, Cushing syndrome and hypothyroidism. Primary aldosteronism may account for $5-10 \%$ of hypertensive patients is often associated with obesity (194). Testing for primary aldosteronism should be considered in patients with persisting high blood pressure despite treatment with three antihypertensive drugs and other suggestive features of primary aldosteronism such as hypokalemia, family history or early-onset hypertension, adrenal incidentaloma or presence of obstructive sleep apnoea (195).

Cushing syndrome has many overlapping features with obesity including the presence of hypertension in majority of patients (79); testing for Cushing syndrome should be performed in patients presenting with signs or symptoms consistent with this clinical presentation (chapter 5.3 for details). Hypothyroidism can be accompanied by both obesity and hypertension although none of these conditions is usually severe. Hypertension in hypothyroidism is usually diastolic and may account for up to $1 \%$ of cases of diastolic hypertension (196). Other causes of endocrine hypertension can be present in obesity; nevertheless, these are not characterized by increased prevalence of obesity.

\subsection{Specific conditions}

\subsubsection{Pregnancy}

Pregnancy induces profound changes in endocrine functions that affect not only the gonadotropic axis 
(increase in oestrogens, progesterone and androgens), hormones of lactation (increase in oxytocin and prolactin) and placental hormones (notably human chorionic gonadotropin: HCG), but also other endocrine glands such as the adrenal and thyroid glands. This can lead to false interpretation of hormonal assessments during pregnancy, while most endocrine disorders have heavy consequences on foetal development (197). The deleterious effects of obesity on pregnancy outcomes have been widely described (198). However, few studies have reported the effects of interactions between obesity and pregnancy on endocrine functions.

Concerning thyroid function, during the 1st trimester, HCG induces a transient increase in free thyroid hormones levels and a decrease in TSH. Later, serum free hormones concentrations decrease of approximately $10-15 \%$, and

Table 7 Hormones, aging and obesity.

Endocrine gland/hormones

Thyroid

Gonads

Adrenal glands

Growth hormone

Vitamin D

Ghrelin

\section{Alterations}

Reduced thyroid

hormone production with age

Increased incidence of

hypothyroidism (20)

Decrease in symptoms (206)

Increased cardiac risk (207) but increased TSH is associated with longevity in old people

Controversial role of hypothyroidism and hyperthyroidism in dementia

No specific studies in old obese people

In men: Decreased testosterone secretion (208) and bioavailability (Increased aromatase and SHBG)

Associated with increased risk of sarcopenia and frailty, decline in sexual and cognitive function, increase in BMI, but less bone loss in obesity (209)

In women, decreased oestradiol and progesterone and increased FSH-LH (208)

Increased risk of sarcopenia, but less bone loss in obesity (209)

Increased risk of abdominal unhealthy obesity (210), increased risk of endometrial cancer in obesity (211)

Increased release of ACTH and Cortisol. Decrease of DHEA (208)

Reduction of mineralocorticoid and glucocorticoid receptors

Increased risk of depression, sarcopenic obesity and frailty (215)

Decline of $\mathrm{GH}$ and IGF1 with aging (215)

Role in sarcopenia linked to age and increase frailty (216)

Decreased vitamin D (208)

Aggravates the deficit induced by obesity

Risk of osteoporosis and sarcopenia

Decreased ghrelin (208)

\section{Need to assess}

TSH only as a first step (see chapter 5.2.4)

TSH increases with age but no specific norms for age (45) or for obesity

\section{Need to treat}

Only if overt hypothyroidism (21) or TSH >10 mIU/L in patients with good health status No specificity for obesity in elderly
Only if symptoms (see 5.4)

Age associated norm (212)

No specific norms in obesity

No indication in elderly unless symptoms

Age associated norm (208). No specific norms in obesity (see chapter 5.5)

No indication in elderly unless abnormal symptoms

No specific norm in elderly and obesity (see chapter 5.3)

No indication in elderly

No specific recommendation Systematic supplementation in old in old obese people
Only if low for age and symptomatic (212). Few effects on metabolic disturbances (213)

More cardiovascular side effects in elderly (214)

No recommendations in old obese men

Oestrogen/progesterone therapy may partly prevent change in body composition (210) and decreases the risk of endometrial cancer (211)

No recommendations in old obese women

No indication for DHEA substitution (215)

No specific treatment in old obese people

Promote physical activity

Effect of treatment unclear in elderly and no data in old obese people

No indication

No specific treatment

ACTH, adrenocorticotropic hormone; DHEA, dehydroepiandrosterone; FSH, follicle-stimulating hormone; GH, growth hormone; IGF, insulin-like growth factor; LH, luteinizing hormone; TSH, thyroid-stimulating hormone. 
TSH returns to normal. Thus, most scientific societies recommend specific reference ranges for free thyroid hormones and TSH throughout pregnancy. However, there are no specific ranges for obese pregnant women (199).

Glucocorticoids are vital for normal foetal growth. During pregnancy, a number of endocrine changes induce activation in maternal hypothalamic-pituitaryadrenal (HPA) axis. The foeto-placental unit produces large amounts of steroid and peptide hormones including CRH. The increase in CBG (200), result in a two to threefold increase of plasma cortisol levels and a lesser increase in free cortisol (197). The usual tests are not as easy to interpret during pregnancy. HPA axis activity is reduced in obese pregnancy that could contribute to foetal complications, including macrosomia (201). The systematic assessment of cortisol during pregnancy is not recommended, but obesity can further increase the difficulty to interpret usual tests during pregnancy.

Renin-angiotensin-aldosterone (RAA) axis is activated during pregnancy to compensate vasodilation and to increase extracellular fluid volume. Because, during pregnancy, urine and plasma aldosterone increase, biochemical test results must be correlated with the normal values for pregnancy (197). Alterations of RAA axis have been incriminated in the pathophysiology of preeclampsia that is more prevalent in obese pregnant women. It was notably shown that levels of aldosterone in the third trimester are decreased in obese women with preeclampsia (202).

GH decreases during pregnancy but IGF1 increases because of placental growth hormone production (197). Obesity can further decrease $\mathrm{GH}$, but the consequences are not known.

PTH increases during pregnancy in face of increased calcium and vitamin D demand (203). Around $30 \mathrm{~g}$ of calcium is transferred to the foetus, especially in the last trimester of pregnancy, needed for bone mineralization. No specific data is available in the literature concerning the impact of obesity on PTH regulation during pregnancy, but the decrease of bioavailable vitamin D may impact calcium supply to the foetus, notably after bariatric surgery (204) and a link between calcium status and foetal growth in this population has been shown (205).

\subsubsection{The elderly}

Ageing is associated with alterations of hormonal secretions with variable amplitude for each endocrine system. Furthermore, the symptoms of endocrine disease change with aging and are often less pronounced, which can lead to missing of the diagnosis. The consequences of endocrine diseases can also change in elderly with greater health risks (notably for muscle mass and cardiovascular functions). Finally, the indication to treat is also different, because the benefit to risk ratio may be less favourable.

Obesity may alter the consequences of age-related hormonal changes. Unfortunately, no study has specifically studied the hormonal modification induced by age in obese people. The details of endocrine changes in elderly and potential interactions with obesity is provided in Table 7 .

\section{Declaration of interest}

F C: Receiving research grants and lecturing or advisory board fees, from: Novo Nordisk, Orexigen, Pronokal, Janssen, Ipsen, Pfizer, Member Pituitary Society Executive Committee. M H: Research support: AstraZeneca, BMS, Eli Lilly, Board member/advisory panel/lectures: Amgen, AstraZeneca, Boehringer Ingelheim, Eli Lilly, Johnson \& Johnson, Medtronic, Mundipharma, Novo Nordisk, Sanofi, Takeda. M P: Receipt of grants/ research supports: AstraZeneca, Merck Serono. Receipt of honoraria or consultation fees: MSD, AstraZeneca, Boehringer Ingelheim and Novo Nordisk Participation in a company sponsored speaker's bureau: MSD, AstraZeneca, Boehringer Ingelheim and Novo Nordisk. J S: Consultant activities and lecture fees for Novo Nordisk, Lilly, Janssen, Esteve. F S: research grants, profit studies, advisory boards, participation to meetings for the following pharmaceutical companies: NovoNordisk, Bruno Farmaceutici, Aegerion, Bioitali, Damor Pharmaceuticals. H T: honoraria for lectures and advisory boards from Amgen, Boehringer-Ingelheim, Cheplapharm, Gebro, MSD, Mylan, Novartis, Novonordisk, Sanofi and Takeda. H T has also received institutional fees for clinical studies from Amgen, Boehringer Ingelheim, MSD, Novartis, Novonordisk and Sanofi. Olaf Dekkers is on the editorial board of EJE. Olaf Dekkers was not involved in the review or editorial process for this paper, on which he is listed as an author. The other authors have nothing to disclose.

\section{Funding}

The guideline was sponsored by the European Society of Endocrinology.

\section{Acknowledgements}

The authors of the guideline would like designated experts for their review and additional members of the European Society of Endocrinology for valuable and critical comments.

\section{References}

1 Fruhbeck G, Toplak H, Woodward E, Yumuk V, Maislos M, Oppert JM $\&$ Executive Committee of the European Association for the Study of Obesity. Obesity: the gateway to ill health - an EASO position statement on a rising public health, clinical and scientific challenge in Europe. Obesity Facts 20136 117-120. (https://doi. org/10.1159/000350627)

2 Leitner DR, Fruhbeck G, Yumuk V, Schindler K, Micic D, Woodward E $\&$ Toplak H. Obesity and Type 2 diabetes: two diseases with a need for combined treatment strategies - EASO can lead the way. Obesity Facts 201710 483-492. (https://doi.org/10.1159/000480525) 
3 Yumuk V, Tsigos C, Fried M, Schindler K, Busetto L, Micic D, Toplak H \& Obesity Management Task Force of the European Association for the Study of Obesity. European guidelines for obesity management in adults. Obesity Facts 20158 402-424. (https://doi. org/10.1159/000442721)

4 Hauner H, Woodward E.Looking back - EASO is celebrating its 30th anniversary. Obesity Facts 20169 363-364. (https://doi. org/10.1159/000452647)

5 Marques A, Peralta M, Naia A, Loureiro N \& de Matos MG. Prevalence of adult overweight and obesity in 20 European countries, 2014. European Journal of Public Health 201828 295-300. (https://doi. org/10.1093/eurpub/ckx143)

6 Hebebrand J, Holm JC, Woodward E, Baker JL, Blaak E, Durrer Schutz D, Farpour-Lambert NJ, Frühbeck G, Halford JGC, Lissner L et al. A proposal of the European Association for the study of obesity to improve the ICD-11 diagnostic criteria for obesity based on the three dimensions etiology, degree of adiposity and health risk. Obesity Facts 201710 284-307. (https://doi. org/10.1159/000479208)

7 Buscher AK, Cetiner M, Buscher R, Wingen AM, Hauffa BP \& Hoyer PF. Obesity in patients with Bardet-Biedl syndrome: influence of appetite-regulating hormones. Pediatric Nephrology 201227 2065-2071. (https://doi.org/10.1007/s00467-012-2220-y)

8 Mergen M, Mergen H, Ozata M, Oner R \& Oner C. A novel melanocortin 4 receptor (MC4R) gene mutation associated with morbid obesity. Journal of Clinical Endocrinology and Metabolism 2001 86 3448. (https://doi.org/10.1210/jcem.86.7.7809)

9 Krude H, Biebermann H, Luck W, Horn R, Brabant G \& Gruters A. Severe early-onset obesity, adrenal insufficiency and red hair pigmentation caused by POMC mutations in humans. Nature Genetics 199819 155-157. (https://doi.org/10.1038/509)

10 Martin MG, Lindberg I, Solorzano-Vargas RS, Wang J, Avitzur Y, Bandsma R, Sokollik C, Lawrence S, Pickett LA, Chen Z et al. Congenital proprotein convertase $1 / 3$ deficiency causes malabsorptive diarrhea and other endocrinopathies in a pediatric cohort. Gastroenterology 2013145 138-148. (https://doi. org/10.1053/j.gastro.2013.03.048)

11 Bollerslev J, Rejnmark L, Marcocci C, Shoback DM, Sitges-Serra A, van Biesen W, Dekkers OM \& European Society of Endocrinology. European Society of Endocrinology Clinical Guideline: treatment of chronic hypoparathyroidism in adults. European Journal of Endocrinology 2015 173 G1-G20. (https://doi.org/10.1530/EJE-15-0628)

12 Singh S, Chang SM, Matchar DB \& Bass EB. Chapter 7: grading a body of evidence on diagnostic tests. Journal of General Internal Medicine 201227 (Supplement 1) S47-S55. (https://doi.org/10.1007/ s11606-012-2021-9)

13 Andrews J, Guyatt G, Oxman AD, Alderson P, Dahm P, Falck-Ytter Y, Nasser M, Meerpohl J, Post PN, Kunz R et al. GRADE guidelines: 14. Going from evidence to recommendations: the significance and presentation of recommendations. Journal of Clinical Epidemiology 201366 719-725. (https://doi.org/10.1016/j.jclinepi.2012.03.013)

14 Andrews JC, Schunemann HJ, Oxman AD, Pottie K, Meerpohl JJ, Coello PA, Rind D, Montori VM, Brito JP, Norris S et al. GRADE guidelines: 15. Going from evidence to recommendationdeterminants of a recommendation's direction and strength. Journal of Clinical Epidemiology 201366 726-735. (https://doi.org/10.1016/j. jclinepi.2013.02.003)

15 Guyatt GH, Schunemann HJ, Djulbegovic B \& Akl EA. Guideline panels should not GRADE good practice statements. Journal of Clinical Epidemiology 201568 597-600. (https://doi.org/10.1016/j. jclinepi.2014.12.011)

16 van Hulsteijn L, Pasquali R, Casanueva FF, Haluzik M, Ledoux S, Monteiro M, Salvador J, Santini F, Toplak H \& Dekkers OM. Prevalence of endocrine disorders in obese patients: systematic review and meta-analysis. European Journal of Endocrinology 2019182 11-21. (https://doi.org/10.1530/EJE-19-0666)
17 Pasquali R \& Gambineri A. New perspectives on the definition and management of polycystic ovary syndrome. Journal of Endocrinological Investigation 201841 1123-1135. (https://doi.org/10.1007/s40618018-0832-1)

18 Farebrother J, Zimmermann MB \& Andersson M. Excess iodine intake: sources, assessment, and effects on thyroid function. Annals of the New York Academy of Sciences 20191446 44-65. (https://doi. org/10.1111/nyas.14041)

19 Bray GA, Heisel WE, Afshin A, Jensen MD, Dietz WH, Long M, Kushner RF, Daniels SR, Wadden TA, Tsai AG et al. The science of obesity management: an Endocrine Society scientific statement. Endocrine Reviews 201839 79-132. (https://doi.org/10.1210/ er.2017-00253)

20 Chaker L, Bianco AC, Jonklaas J \& Peeters RP. Hypothyroidism. Lancet 2017390 1550-1562. (https://doi.org/10.1016/S01406736(17)30703-1)

21 Pearce SH, Brabant G, Duntas LH, Monzani F, Peeters RP, Razvi S \& Wemeau JL. 2013 ETA guideline: management of subclinical hypothyroidism. European Thyroid Journal 201320132 215-228. (https://doi.org/10.1159/000356507)

22 Garmendia Madariaga A, Santos Palacios S, Guillen-Grima F \& Galofre JC. The incidence and prevalence of thyroid dysfunction in Europe: a meta-analysis. Journal of Clinical Endocrinology and Metabolism 201499 923-931. (https://doi.org/10.1210/jc.2013-2409)

23 Okosieme O, Gilbert J, Abraham P, Boelaert K, Dayan C, Gurnell M, Leese G, McCabe C, Perros P, Smith V et al. Management of primary hypothyroidism: statement by the British Thyroid Association Executive Committee. Clinical Endocrinology 201684 799-808. (https://doi.org/10.1111/cen.12824)

24 Garber JR, Cobin RH, Gharib H, Hennessey JV, Klein I, Mechanick JI, Pessah-Pollack R, Singer PA \& Woeber for the American Association KA. Clinical practice guidelines for hypothyroidism in adults: cosponsored by the American Association of Clinical Endocrinologists and the American Thyroid Association. Thyroid 201222 1200-1235. (https://doi.org/10.1089/thy.2012.0205)

25 Hennessey JV, Garber JR, Woeber KA, Cobin R, Klein I, AACE Thyroid Scientific Committee \& American College of Endocrinology (ACE). American Association of Clinical Endocrinologists and American College of Endocrinology position statement on thyroid dysfunction case finding. Endocrine Practice 201622 262-270. (https://doi. org/10.4158/EP151038.PS)

26 Michalaki MA, Vagenakis AG, Leonardou AS, Argentou MN, Habeos IG, Makri MG, Psyrogiannis AI, Kalfarentzos FE \& Kyriazopoulou VE. Thyroid function in humans with morbid obesity. Thyroid 200616 73-78. (https://doi.org/10.1089/thy.2006.16.73)

27 Duntas LH \& Biondi B. The interconnections between obesity, thyroid function, and autoimmunity: the multifold role of leptin. Thyroid 201323 646-653. (https://doi.org/10.1089/thy.2011.0499)

28 Zulewski H, Muller B, Exer P, Miserez AR \& Staub JJ. Estimation of tissue hypothyroidism by a new clinical score: evaluation of patients with various grades of hypothyroidism and controls. Journal of Clinical Endocrinology and Metabolism 199782 771-776. (https://doi. org/10.1210/jcem.82.3.3810)

29 Karmisholt J, Andersen S \& Laurberg P. Weight loss after therapy of hypothyroidism is mainly caused by excretion of excess body water associated with myxoedema. Journal of Clinical Endocrinology and Metabolism 201196 E99-E103. (https://doi.org/10.1210/ jc.2010-1521)

30 Hoogwerf BJ \& Nuttall FQ. Long-term weight regulation in treated hyperthyroid and hypothyroid subjects. American Journal of Medicine 198476 963-970. (https://doi.org/10.1016/0002-9343(84)90842-8)

31 Lee SY, Braverman LE \& Pearce EN. Changes in body weight after treatment of primary hypothyroidism with levothyroxine. Endocrine Practice 201420 1122-1128. (https://doi.org/10.4158/EP14072.OR)

32 de Moura Souza A \& Sichieri R. Association between serum TSH concentration within the normal range and adiposity. European 
Journal of Endocrinology 2011165 11-15. (https://doi.org/10.1530/ EJE-11-0261)

33 Taylor PN, Razvi S, Pearce SH \& Dayan CM. Clinical review: a review of the clinical consequences of variation in thyroid function within the reference range. Journal of Clinical Endocrinology and Metabolism 201398 3562-3571. (https://doi.org/10.1210/jc.2013-1315)

34 al-Adsani H, Hoffer LJ \& Silva JE. Resting energy expenditure is sensitive to small dose changes in patients on chronic thyroid hormone replacement. Journal of Clinical Endocrinology and Metabolism 199782 1118-1125. (https://doi.org/10.1210/ jcem.82.4.3873)

35 Tiller D, Ittermann T, Greiser KH, Meisinger C, Agger C, Hofman A, Thuesen B, Linneberg A, Peeters R, Franco O et al. Association of serum thyrotropin with anthropometric markers of obesity in the general population. Thyroid 201626 1205-1214. (https://doi. org/10.1089/thy.2015.0410)

36 Neves JS, Castro Oliveira S, Souteiro P, Pedro J, Magalhaes D, Guerreiro V, Bettencourt-Silva R, Costa MM, Cristina Santos A, Queirós J et al. Effect of weight loss after bariatric surgery on thyroidstimulating hormone levels in patients with morbid obesity and normal thyroid function. Obesity Surgery 201828 97-103. (https:// doi.org/10.1007/s11695-017-2792-5)

37 Soriguer F, Valdes S, Morcillo S, Esteva I, Almaraz MC, de Adana MS, Tapia MJ, Dominguez M, Gutierrez-Repiso C, Rubio-Martin E et al. Thyroid hormone levels predict the change in body weight: a prospective study. European Journal of Clinical Investigation 201141 1202-1209. (https://doi.org/10.1111/j.1365-2362.2011.02526.x)

38 Marzullo P, Minocci A, Mele C, Fessehatsion R, Tagliaferri M, Pagano L, Scacchi M, Aimaretti G \& Sartorio A. The relationship between resting energy expenditure and thyroid hormones in response to short-term weight loss in severe obesity. PLoS ONE 2018 13 e0205293. (https://doi.org/10.1371/journal.pone.0205293)

39 Kok P, Roelfsema F, Langendonk JG, Frolich M, Burggraaf J, Meinders AE \& Pijl H. High circulating thyrotropin levels in obese women are reduced after body weight loss induced by caloric restriction. Journal of Clinical Endocrinology and Metabolism 200590 4659-4663. (https://doi.org/10.1210/jc.2005-0920)

40 Poddar M, Chetty Y \& Chetty VT. How does obesity affect the endocrine system? A narrative review. Clinical Obesity $2017 \mathbf{7}$ 136-144. (https://doi.org/10.1111/cob.12184)

41 Santini F, Marzullo P, Rotondi M, Ceccarini G, Pagano L, Ippolito S, Chiovato L \& Biondi B. Mechanisms in endocrinology: the crosstalk between thyroid gland and adipose tissue: signal integration in health and disease. European Journal of Endocrinology 2014171 R137-R152. (https://doi.org/10.1530/EJE-14-0067)

42 Rugge JB, Bougatsos C \& Chou R. Screening and treatment of thyroid dysfunction: an evidence review for the U.S. Preventive Services Task Force. Annals of Internal Medicine 2015162 35-45. (https://doi. org/10.7326/M14-1456)

43 Rahbar AR, Kalantarhormozi M, Izadi F, Arkia E, Rashidi M, Pourbehi F, Daneshifard F \& Rahbar A. Relationship between body mass index, waist-to-hip ratio, and serum lipid concentrations and thyroid-stimulating hormone in the euthyroid adult population. Iranian Journal of Medical Sciences 201742 301-305.

44 Gutch M, Rungta S, Kumar S, Agarwal A, Bhattacharya A \& Razi SM. Thyroid functions and serum lipid profile in metabolic syndrome. Biomedical Journal 201740 147-153. (https://doi.org/10.1016/j. bj.2016.12.006)

45 LeFevre ML \& U.S. Preventive Services Task Force. Screening for thyroid dysfunction: U.S. Preventive Services Task Force recommendation statement. Annals of Internal Medicine 2015162 641-650. (https://doi.org/10.7326/M15-0483)

46 Persani L, Brabant G, Dattani M, Bonomi M, FeldtRasmussen U, Fliers E, Gruters A, Maiter D, Schoenmakers N \& van Trotsenburg ASP. 2018 European Thyroid Association (ETA) guidelines on the diagnosis and management of central hypothyroidism. European Thyroid Journal 201820187 225-237. (https://doi.org/10.1159/000491388)

47 Hollowell JG, Staehling NW, Flanders WD, Hannon WH, Gunter EW, Spencer CA \& Braverman LE. Serum TSH, T(4), and thyroid antibodies in the United States population (1988 to 1994): national Health and Nutrition Examination Survey (NHANES III). Journal of Clinical Endocrinology and Metabolism 200287 489-499. (https://doi. org/10.1210/jcem.87.2.8182)

48 Rotondi M, Leporati P, La Manna A, Pirali B, Mondello T, Fonte R, Magri F \& Chiovato L. Raised serum TSH levels in patients with morbid obesity: is it enough to diagnose subclinical hypothyroidism? European Journal of Endocrinology 2009160 403-408. (https://doi. org/10.1530/EJE-08-0734)

49 Marzullo P, Minocci A, Tagliaferri MA, Guzzaloni G, Di Blasio A, De Medici C, Aimaretti G \& Liuzzi A. Investigations of thyroid hormones and antibodies in obesity: leptin levels are associated with thyroid autoimmunity independent of bioanthropometric, hormonal, and weight-related determinants. Journal of Clinical Endocrinology and Metabolism 201095 3965-3972. (https://doi. org/10.1210/jc.2009-2798)

50 Ehlers M, Jordan AL, Feldkamp J, Fritzen R, Quadbeck B, Haase M, Allelein S, Schmid C \& Schott M. Anti-thyroperoxidase antibody levels $>500 \mathrm{IU} / \mathrm{ml}$ indicate a moderately increased risk for developing hypothyroidism in autoimmune thyroiditis. Hormone and Metabolic Research 201648 623-629. (https://doi.org/10.1055/s-0042-112815)

51 Mancini A, Di Segni C, Raimondo S, Olivieri G, Silvestrini A, Meucci E \& Currò D. Thyroid hormones, oxidative stress, and inflammation. Mediators of Inflammation 201620166757154. (https://doi.org/10.1155/2016/6757154)

52 Keskek ŞÖ, Kursun Ö, Ortoglu G, Bankir M, Tuzun Z \& Saler T. Obesity without comorbidity may also lead to non-thyroidal illness syndrome. Advances in Clinical and Experimental Medicine 201827 1515-1520. (https://doi.org/10.17219/acem/70226)

53 Valdes S, Maldonado-Araque C, Lago-Sampedro A, Lillo-Munoz JA, Garcia-Fuentes E, Perez-Valero V, Gutiérrez-Repiso C, GarciaEscobar E, Goday A, Urrutia I et al. Reference values for TSH may be inadequate to define hypothyroidism in persons with morbid obesity: Di@bet.es study. Obesity 201725 788-793. (https://doi. org/10.1002/oby.21796)

54 Santini F, Pinchera A, Marsili A, Ceccarini G, Castagna MG, Valeriano R, Giannetti M, Taddei D, Centoni R, Scartabelli G et al. Lean body mass is a major determinant of levothyroxine dosage in the treatment of thyroid diseases. Journal of Clinical Endocrinology and Metabolism 200590 124-127. (https://doi.org/10.1210/jc.2004-1306)

55 Bekkering GE, Agoritsas T, Lytvyn L, Heen AF, Feller M, Moutzouri E, Abdulazeem H, Aertgeerts B, Beecher D, Brito JP et al. Thyroid hormones treatment for subclinical hypothyroidism: a clinical practice guideline. BMJ 2019365 12006. (https://doi.org/10.1136/ bmj.12006)

56 Wiersinga WM, Duntas L, Fadeyev V, Nygaard B \& Vanderpump MP. 2012 ETA guidelines: the use of L-T4 + L-T3 in the treatment of hypothyroidism. European Thyroid Journal 20121 55-71. (https://doi. org/10.1159/000339444)

57 Fierabracci P, Martinelli S, Tamberi A, Piaggi P, Basolo A, Pelosini C, Ricco I, Magno S, Querci G, Ceccarini G et al. Weight loss and variation of levothyroxine requirements in hypothyroid obese patients after bariatric surgery. Thyroid 201626 499-503. (https://doi. org/10.1089/thy.2015.0473)

58 Moore R, Grant AM, Howard AN \& Mills IH. Treatment of obesity with triiodothyronine and a very-low-calorie liquid formula diet. Lancet 19801 223-226. (https://doi.org/10.1016/s01406736(80)90715-1)

59 Koppeschaar HP, Meinders AE \& Schwarz F. Metabolic responses in grossly obese subjects treated with a very-low-calorie diet with and without triiodothyronine treatment. International Journal of Obesity 19837 133-141. 
60 Koppeschaar HP, Meinders AE \& Schwarz F. The effect of a lowcalorie diet alone and in combination with triiodothyronine therapy on weight loss and hypophyseal thyroid function in obesity. International Journal of Obesity 19837 123-131.

61 Sawin CT, Geller A, Wolf PA, Belanger AJ, Baker E, Bacharach P, Wilson PW, Benjamin EJ \& D'Agostino RB. Low serum thyrotropin concentrations as a risk factor for atrial fibrillation in older persons. New England Journal of Medicine 1994331 1249-1252. (https://doi. org/10.1056/NEJM199411103311901)

62 Muller TD, Clemmensen C, Finan B, DiMarchi RD \& Tschop MH. Anti-obesity therapy: from rainbow pills to polyagonists. Pharmacological Reviews 201870 712-746. (https://doi.org/10.1124/ pr.117.014803)

63 Vanderpump MP, Tunbridge WM, French JM, Appleton D, Bates D, Clark F, Grimley Evans J, Hasan DM, Rodgers H \& Tunbridge F. The incidence of thyroid disorders in the community: a twenty-year follow-up of the Whickham Survey. Clinical Endocrinology 199543 55-68. (https://doi.org/10.1111/j.1365-2265.1995.tb01894.x)

64 Niranjan U \& Wright NP. Should we treat subclinical hypothyroidism in obese children? BMJ 2016352 i941. (https://doi.org/10.1136/bmj.i941)

65 Feller M, Snel M, Moutzouri E, Bauer DC, de Montmollin M, Aujesky D, Ford I, Gussekloo J, Kearney PM, Mooijaart S et al. Association of thyroid hormone therapy with quality of life and thyroid-related symptoms in patients with subclinical hypothyroidism: a systematic review and meta-analysis. JAMA 2018 320 1349-1359. (https://doi.org/10.1001/jama.2018.13770)

66 Chu JW \& Crapo LM. The treatment of subclinical hypothyroidism is seldom necessary. Journal of Clinical Endocrinology and Metabolism 200186 4591-4599. (https://doi.org/10.1210/jcem.86.10.7961)

67 Walsh JP, Bremner AP, Feddema P, Leedman PJ, Brown SJ \& O'Leary P. Thyrotropin and thyroid antibodies as predictors of hypothyroidism: a 13-year, longitudinal study of a communitybased cohort using current immunoassay techniques. Journal of Clinical Endocrinology and Metabolism 201095 1095-1104. (https:// doi.org/10.1210/jc.2009-1977)

68 Calsolaro V, Niccolai F, Pasqualetti G, Tognini S, Magno S, Riccioni T, Bottari M, Caraccio N \& Monzani F. Hypothyroidism in the elderly: who should be treated and how? Journal of the Endocrine Society 2019 3 146-158. (https://doi.org/10.1210/js.2018-00207)

69 Stott DJ, Rodondi N, Kearney PM, Ford I, Westendorp RGJ, Mooijaart SP, Sattar N, Aubert CE, Aujesky D, Bauer DC et al. Thyroid hormone therapy for older adults with subclinical hypothyroidism. New England Journal of Medicine 2017376 2534-2544. (https://doi. org/10.1056/NEJMoa1603825)

70 Maraka S, Singh Ospina NM, Mastorakos G \& O'Keeffe DT. Subclinical hypothyroidism in women planning conception and during pregnancy: who should be treated and how? Journal of the Endocrine Society 20182 533-546. (https://doi.org/10.1210/js.2018-00090)

71 Rosario PW, Carvalho M \& Calsolari MR. Natural history of subclinical hypothyroidism with $\mathrm{TSH} \leq 10 \mathrm{mIU} / \mathrm{l}$ : a prospective study $\leq 10$ mIU/l. Clinical Endocrinology 201684 878-881. (https://doi. org/10.1111/cen.12939)

72 Paschou SA, Vryonidou A \& Goulis DG. Thyroid nodules: alpha guide to assessment, treatment and follow-up. Maturitas 201796 1-9. (https://doi.org/10.1016/j.maturitas.2016.11.002)

73 Rotondi M, Cappelli C, Leporati P, Chytiris S, Zerbini F, Fonte R, Magri F, Castellano M \& Chiovato L. A hypoechoic pattern of the thyroid at ultrasound does not indicate autoimmune thyroid diseases in patients with morbid obesity. European Journal of Endocrinology 2010163 105-109. (https://doi.org/10.1530/EJE-10-0288)

74 Kyrou I, Adesanya O, Hedley N, Wayte S, Grammatopoulos D, Thomas CL, Weedall A, Sivaraman S, Pelluri L, Barber TM et al. Improved thyroid hypoechogenicity following bariatric-induced weight loss in euthyroid adults with severe obesity-a pilot study. Frontiers in Endocrinology 20189 488. (https://doi.org/10.3389/ fendo.2018.00488)
75 Schmid D, Ricci C, Behrens G \& Leitzmann MF. Adiposity and risk of thyroid cancer: a systematic review and meta-analysis. Obesity Reviews 201516 1042-1054. (https://doi.org/10.1111/obr.12321)

76 Grani G, Lamartina L, Montesano T, Ronga G, Maggisano V, Falcone R, Ramundo V, Giacomelli L, Durante C, Russo D et al. Lack of association between obesity and aggressiveness of differentiated thyroid cancer. Journal of Endocrinological Investigation 201942 85-90. (https://doi.org/10.1007/s40618-018-0889-x)

77 Chabre O. The difficulties of pseudo-Cushing's syndrome (or 'nonneoplastic hypercortisolism'). Annales d'Endocrinologie 201879 138-145. (https://doi.org/10.1016/j.ando.2018.04.017)

78 Nieman LK, Biller BM, Findling JW, Newell-Price J, Savage MO, Stewart PM \& Montori VM. The diagnosis of Cushing's syndrome: an Endocrine Society Clinical Practice Guideline. Journal of Clinical Endocrinology and Metabolism 200893 1526-1540. (https://doi. org/10.1210/jc.2008-0125)

79 Lacroix A, Feelders RA, Stratakis CA \& Nieman LK. Cushing's syndrome. Lancet 2015386 913-927. (https://doi.org/10.1016/ S0140-6736(14)61375-1)

80 Tiryakioglu O, Ugurlu S, Yalin S, Yirmibescik S, Caglar E, Yetkin DO $\&$ Kadioglu P. Screening for Cushing's syndrome in obese patients. Clinics 201065 9-13. (https://doi.org/10.1590/S1807$59322010000100003)$

81 Lammert A, Nittka S, Otto M, Schneider-Lindner V, Kemmer A, Kramer BK, Birck R, Hammes HP \& Benck U. Performance of the 1 mg dexamethasone suppression test in patients with severe obesity. Obesity 201624 850-855. (https://doi.org/10.1002/oby.21442)

82 Jankovic D, Wolf P, Anderwald CH, Winhofer Y, PromintzerSchifferl M, Hofer A, Langer F, Prager G, Ludvik B, Gessl A et al. Prevalence of endocrine disorders in morbidly obese patients and the effects of bariatric surgery on endocrine and metabolic parameters. Obesity Surgery 201222 62-69. (https://doi.org/10.1007/ s11695-011-0545-4)

83 Catargi B, Rigalleau V, Poussin A, Ronci-Chaix N, Bex V, Vergnot V, Gin H, Roger P \& Tabarin A. Occult Cushing's syndrome in type-2 diabetes. Journal of Clinical Endocrinology and Metabolism $2003 \mathbf{8 8}$ 5808-5813. (https://doi.org/10.1210/jc.2003-030254)

84 Leibowitz G, Tsur A, Chayen SD, Salameh M, Raz I, Cerasi E \& Gross DJ. Pre-clinical Cushing's syndrome: an unexpected frequent cause of poor glycaemic control in obese diabetic patients. Clinical Endocrinology 199644 717-722. (https://doi.org/10.1046/j.13652265.1996.737558.x)

85 Steffensen C, Pereira AM, Dekkers OM \& Jorgensen JO. DIAGNOSIS of ENDOCRINE DISEASE: Prevalence of hypercortisolism in type 2 diabetes patients: a systematic review and meta-analysis. European Journal of Endocrinology 2016175 R247-R253. (https://doi. org/10.1530/EJE-16-0434)

86 Caetano MS, Silva Rdo Rdo C \& Kater CE. Increased diagnostic probability of subclinical Cushing's syndrome in a population sample of overweight adult patients with type 2 diabetes mellitus. Arquivos Brasileiros de Endocrinologia e Metabologia 200751 11181127. (https://doi.org/10.1590/s0004-27302007000700015)

87 Debono M \& Newell-Price JD. Cushing's syndrome: where and how to find it. Frontiers of Hormone Research 201646 15-27. (https://doi. org/10.1159/000443861)

88 Loriaux DL. Diagnosis and differential diagnosis of Cushing's syndrome. New England Journal of Medicine 2017376 1451-1459. (https://doi.org/10.1056/NEJMra1505550)

89 Fleseriu M, Ludlam WH, Teh SH, Yedinak CG, Deveney C \& Sheppard BC. Cushing's syndrome might be underappreciated in patients seeking bariatric surgery: a plea for screening. Surgery for Obesity and Related Diseases 20095 116-119. (https://doi. org/10.1016/j.soard.2008.09.011)

90 Savastano S, Pivonello R \& Colao A. Bariatric surgery for obesity and hidden Cushing syndrome. Surgery for Obesity and Related Diseases 20095 121-122. (https://doi.org/10.1016/j.soard.2008.07.006) 
91 Fierabracci P, Pinchera A, Martinelli S, Scartabelli G, Salvetti G, Giannetti M, Pucci A, Galli G, Ricco I, Querci G et al. Prevalence of endocrine diseases in morbidly obese patients scheduled for bariatric surgery: beyond diabetes. Obesity Surgery 201121 54-60. (https://doi. org/10.1007/s11695-010-0297-6)

92 Javorsky BR, Carroll TB, Tritos NA, Salvatori R, Heaney AP, Fleseriu M, Biller BM \& Findling JW. Discovery of Cushing's syndrome after bariatric surgery: multicenter series of 16 patients. Obesity Surgery 201525 2306-2313. (https://doi.org/10.1007/s11695-015-1681-z)

93 Shimon I. Screening for Cushing's syndrome: is it worthwhile? Pituitary 201518 201-205. (https://doi.org/10.1007/s11102-0150634-9)

94 Incollingo Rodriguez AC, Epel ES, White ML, Standen EC, Seckl JR \& Tomiyama AJ. Hypothalamic-pituitary-adrenal axis dysregulation and cortisol activity in obesity: a systematic review. Psychoneuroendocrinology 201562 301-318. (https://doi. org/10.1016/j.psyneuen.2015.08.014)

95 van Rossum EF. Obesity and cortisol: new perspectives on an old theme. Obesity 201725 500-501. (https://doi.org/10.1002/ oby.21774)

96 Fassnacht M, Arlt W, Bancos I, Dralle H, Newell-Price J, Sahdev A et al. Management of adrenal incidentalomas: European Society of Endocrinology Clinical Practice Guideline in collaboration with the European Network for the Study of Adrenal Tumors. European Journal of Endocrinology 2016175 G1-G34. (https://doi.org/10.1530/EJE-16-0467)

97 Urwyler SA, Cupa N \& Christ-Crain M. Comparison of $1 \mathrm{mg}$ versus $2 \mathrm{mg}$ dexamethasone suppression test in patients with obesity. Hormone and Metabolic Research 201749 854-859. (https://doi. org/10.1055/s-0043-119128)

98 Pasquali R, Ambrosi B, Armanini D, Cavagnini F, Uberti ED, Del Rio G, de Pergola G, Maccario M, Mantero F, Marugo M et al. Cortisol and ACTH response to oral dexamethasone in obesity and effects of sex, body fat distribution, and dexamethasone concentrations: a dose-response study. Journal of Clinical Endocrinology and Metabolism 200287 166-175. (https://doi.org/10.1210/jcem.87.1.8158)

99 Belvederi Murri M, Prestia D, Mondelli V, Pariante C, Patti S, Olivieri B, Arzani C, Masotti M, Respino M, Antonioli M et al. The HPA axis in bipolar disorder: systematic review and metaanalysis. Psychoneuroendocrinology 201663 327-342. (https://doi. org/10.1016/j.psyneuen.2015.10.014)

100 Findling JW \& Raff H. Differentiation of pathologic/neoplastic hypercortisolism (Cushing syndrome) from physiologic/nonneoplastic hypercortisolism (formerly known as Pseudo-Cushing syndrome): response to Letter to the Editor. European Journal of Endocrinology 2018178 L3. (https://doi.org/10.1530/EJE-17-1034)

101 Tamada D, Otsuki M, Kashine S, Hirata A, Onodera T, Kitamura T \& Shimomura I. Obstructive sleep apnea syndrome causes a pseudoCushing's state in Japanese obese patients with type 2 diabetes mellitus. Endocrine Journal 201360 1289-1294. (https://doi. org/10.1507/endocrj.ej13-0255)

102 Rask E, Olsson T, Soderberg S, Andrew R, Livingstone DE, Johnson O $\&$ Walker BR. Tissue-specific dysregulation of cortisol metabolism in human obesity. Journal of Clinical Endocrinology and Metabolism 2001 86 1418-1421. (https://doi.org/10.1210/jcem.86.3.7453)

103 Douyon L \& Schteingart DE. Effect of obesity and starvation on thyroid hormone, growth hormone, and cortisol secretion. Endocrinology and Metabolism Clinics of North America 200231 173-189. (https://doi.org/10.1016/s0889-8529(01)00023-8)

104 Dinnes J, Bancos I, Ferrante di Ruffano L, Chortis V, Davenport C, Bayliss S, Sahdev A, Guest P, Fassnacht M, Deeks JJ et al. MANAGEMENT of ENDOCRINE DISEASE: Imaging for the diagnosis of malignancy in incidentally discovered adrenal masses: a systematic review and meta-analysis. European Journal of Endocrinology 2016175 R51-R64. (https://doi.org/10.1530/EJE-16-0461)

105 Iacobone M, Citton M, Scarpa M, Viel G, Boscaro M \& Nitti D. Systematic review of surgical treatment of subclinical Cushing's syndrome. British Journal of Surgery 2015102 318-330. (https://doi. org/10.1002/bjs.9742)

106 Fein HG, Vaughan 3rd TB, Kushner H, Cram D \& Nguyen D. Sustained weight loss in patients treated with mifepristone for Cushing's syndrome: a follow-up analysis of the SEISMIC study and long-term extension. BMC Endocrine Disorders 201515 63. (https:// doi.org/10.1186/s12902-015-0059-5)

107 Calderón B, Gómez-Martín JM, Vega-Piñero B, Martín-Hidalgo A, Galindo J, Luque-Ramírez M, Escobar-Morreale HF \& BotellaCarretero JI. Prevalence of male secondary hypogonadism in moderate to severe obesity and its relationship with insulin resistance and excess body weight. Andrology 20164 62-67. (https:// doi.org/10.1111/andr.12135)

108 Liu Y \& Ding Z. Obesity, a serious etiologic factor for male subfertility in modern society. Reproduction 2017154 R123-R131. (https://doi. org/10.1530/REP-17-0161)

109 Dandona P \& Dhindsa S. Update: hypogonadotropic hypogonadism in type 2 diabetes and obesity. Journal of Clinical Endocrinology and Metabolism 201196 2643-2651. (https://doi.org/10.1210/jc.20102724)

110 Luconi M, Samavat J, Seghieri G, Iannuzzi G, Lucchese M, Rotella C, Forti G, Maggi M \& Mannucci E. Determinants of testosterone recovery after bariatric surgery: is it only a matter of reduction of body mass index? Fertility and Sterility 201399 1872.e1-1879.e1. (https://doi.org/10.1016/j.fertnstert.2013.02.039)

111 Bhasin S, Brito JP, Cunningham GR, Hayes FJ, Hodis HN, Matsumoto AM, Snyder PJ, Swerdloff RS, Wu FC \& Yialamas MA. Testosterone therapy in men with hypogonadism: an Endocrine Society clinical practice guideline. Journal of Clinical Endocrinology and Metabolism 2018103 1715-1744. (https://doi.org/10.1210/ jc.2018-00229)

112 Couillard C, Gagnon J, Bergeron J, Leon AS, Rao DC, Skinner JS, Wilmore JH, Després JP \& Bouchard C. Contribution of body fatness and adipose tissue distribution to the age variation in plasma steroid hormone concentrations in men: the HERITAGE Family Study. Journal of Clinical Endocrinology and Metabolism 200085 1026-1031. (https://doi.org/10.1210/jcem.85.3.6427)

113 Dhindsa S, Ghanim H, Batra M \& Dandona P. Hypogonadotropic hypogonadism in men with diabesity. Diabetes Care 201841 1516-1525. (https://doi.org/10.2337/dc17-2510)

114 Nielsen TL, Hagen C, Wraae K, Brixen K, Petersen PH, Haug E, Larsen R \& Andersen M. Visceral and subcutaneous adipose tissue assessed by magnetic resonance imaging in relation to circulating androgens, sex hormone-binding globulin, and luteinizing hormone in young men. Journal of Clinical Endocrinology and Metabolism 2007 92 2696-2705. (https://doi.org/10.1210/jc.2006-1847)

115 Tsai EC, Boyko EJ, Leonetti DL \& Fujimoto WY. Low serum testosterone level as a predictor of increased visceral fat in JapaneseAmerican men. International Journal of Obesity and Related Metabolic Disorders 200024 485-491. (https://doi.org/10.1038/sj.ijo.0801183)

116 Yeap BB, Grossmann M, McLachlan RI, Handelsman DJ, Wittert GA, Conway AJ, Stuckey BG, Lording DW, Allan CA, Zajac JD et al. Endocrine Society of Australia position statement on male hypogonadism (Part 1): assessment and indications for testosterone therapy. Medical Journal of Australia 2016205 173-178. (https://doi. org/10.5694/mja16.00393)

117 De Lorenzo A, Noce A, Moriconi E, Rampello T, Marrone G, Di Daniele N \& Rovella V. MOSH syndrome (male obesity secondary hypogonadism): clinical assessment and possible therapeutic approaches. Nutrients 201810 E474. (https://doi.org/10.3390/ nu10040474)

118 Wu FC, Tajar A, Beynon JM, Pye SR, Silman AJ, Finn JD, O’Neill TW, Bartfai G, Casanueva FF, Forti G et al. Identification of late-onset hypogonadism in middle-aged and elderly men. New England Journal of Medicine 2010363 123-135. (https://doi.org/10.1056/ NEJMoa0911101) 
119 Morales A, Bebb RA, Manjoo P, Assimakopoulos P, Axler J, Collier C, Elliott S, Goldenberg L, Gottesman I, Grober ED et al. Diagnosis and management of testosterone deficiency syndrome in men: clinical practice guideline. Canadian Medical Association Journal 2015187 1369-1377. (https://doi.org/10.1503/cmaj.150033)

120 Tenover JS, Matsumoto AM, Clifton DK \& Bremner WJ. Age-related alterations in the circadian rhythms of pulsatile luteinizing hormone and testosterone secretion in healthy men. Journal of Gerontology 198843 M163-M169. (https://doi.org/10.1093/geronj/43.6.m163)

121 Rastrelli G, O’Neill TW, Ahern T, Bartfai G, Casanueva FF, Forti G, Keevil B, Giwercman A, Han TS, Slowikowska-Hilczer J et al. Symptomatic androgen deficiency develops only when both total and free testosterone decline in obese men who may have incident biochemical secondary hypogonadism: prospective results from the EMAS. Clinical Endocrinology 201889 459-469. (https://doi. org/10.1111/cen.13756)

122 Antonio L, Wu FC, O’Neill TW, Pye SR, Ahern TB, Laurent MR, Huhtaniemi IT, Lean ME, Keevil BG, Rastrelli G et al. Low free testosterone is associated with hypogonadal signs and symptoms in men with normal total testosterone. Journal of Clinical Endocrinology and Metabolism 2016101 2647-2657. (https://doi.org/10.1210/ jc. 2015-4106)

123 Vermeulen A, Verdonck L \& Kaufman JM. A critical evaluation of simple methods for the estimation of free testosterone in serum. Journal of Clinical Endocrinology and Metabolism 199984 3666-3672. (https://doi.org/10.1210/jcem.84.10.6079)

124 Bhasin S, Pencina M, Jasuja GK, Travison TG, Coviello A, Orwoll E, Wang PY, Nielson C, Wu F, Tajar A et al. Reference ranges for testosterone in men generated using liquid chromatography tandem mass spectrometry in a community-based sample of healthy nonobese young men in the Framingham Heart Study and applied to three geographically distinct cohorts. Journal of Clinical Endocrinology and Metabolism 201196 2430-2439. (https://doi.org/10.1210/jc.2010-3012)

125 Travison TG, Vesper HW, Orwoll E, Wu F, Kaufman JM, Wang Y, Lapauw B, Fiers T, Matsumoto AM \& Bhasin S. Harmonized reference ranges for circulating testosterone levels in men of four cohort studies in the United States and Europe. Journal of Clinical Endocrinology and Metabolism 2017102 1161-1173. (https://doi. org/10.1210/jc.2016-2935)

126 Trost LW \& Mulhall JP. Challenges in testosterone measurement, data interpretation, and methodological appraisal of interventional trials. Journal of Sexual Medicine 201613 1029-1046. (https://doi. org/10.1016/j.jsxm.2016.04.068)

127 Wang C, Catlin DH, Demers LM, Starcevic B \& Swerdloff RS. Measurement of total serum testosterone in adult men: comparison of current laboratory methods versus liquid chromatography-tandem mass spectrometry. Journal of Clinical Endocrinology and Metabolism 200489 534-543. (https://doi.org/10.1210/jc.2003-031287)

128 Yeap BB, Alfonso H, Chubb SA, Handelsman DJ, Hankey GJ, Norman PE \& Flicker L. Reference ranges and determinants of testosterone, dihydrotestosterone, and estradiol levels measured using liquid chromatography-tandem mass spectrometry in a population-based cohort of older men. Journal of Clinical Endocrinology and Metabolism 201297 4030-4039. (https://doi. org/10.1210/jc.2012-2265)

129 Svartberg J, von Mühlen D, Sundsfjord J \& Jorde R. Waist circumference and testosterone levels in community dwelling men. The Tromsø study. European Journal of Epidemiology 200419 657-663. (https://doi.org/10.1023/b:ejep.0000036809.30558.8f)

130 Eriksson J, Haring R, Grarup N, Vandenput L, Wallaschofski H, Lorentzen E, Hansen T, Mellström D, Pedersen O, Nauck M et al. Causal relationship between obesity and serum testosterone status in men: a bi-directional Mendelian randomization analysis. PLOS ONE 201712 e0176277. (https://doi.org/10.1371/journal.pone.0176277)

131 Corona G, Rastrelli G, Monami M, Saad F, Luconi M, Lucchese M, Facchiano E, Sforza A, Forti G, Mannucci E et al. Body weight loss reverts obesity-associated hypogonadotropic hypogonadism: a systematic review and meta-analysis. European Journal of Endocrinology 2013168 829-843. (https://doi.org/10.1530/EJE-12-0955)

132 Fui MNT, Prendergast LA, Dupuis P, Raval M, Strauss BJ, Zajac JD \& Grossmann M. Effects of testosterone treatment on body fat and lean mass in obese men on a hypocaloric diet: a randomised controlled trial. BMC Medicine 201614 153. (https://doi.org/10.1186/s12916-016-0700-9)

$133 \mathrm{Ng}$ Tang Fui M, Hoermann R, Zajac JD \& Grossmann M. The effects of testosterone on body composition in obese men are not sustained after cessation of testosterone treatment. Clinical Endocrinology 2017 87 336-343. (https://doi.org/10.1111/cen.13385)

134 Pellitero S, Olaizola I, Alastrue A, Martínez E, Granada ML, Balibrea JM, Moreno P, Serra A, Navarro-Díaz M, Romero R et al. Hypogonadotropic hypogonadism in morbidly obese males is reversed after bariatric surgery. Obesity Surgery 201222 1835-1842. (https://doi.org/10.1007/s11695-012-0734-9)

135 Calderón B, Galdón A, Calañas A, Peromingo R, Galindo J, GarcíaMoreno F, Rodriguez-Velasco G, Martín-Hidalgo A, Vazquez C, Escobar-Morreale HF et al. Effects of bariatric surgery on male obesity-associated secondary hypogonadism: comparison of laparoscopic gastric bypass with restrictive procedures. Obesity Surgery 201424 1686-1692. (https://doi.org/10.1007/s11695-014-1233-y)

136 Samavat J, Facchiano E, Lucchese M, Forti G, Mannucci E, Maggi M $\&$ Luconi M. Hypogonadism as an additional indication for bariatric surgery in male morbid obesity? European Journal of Endocrinology 2014171 555-560. (https://doi.org/10.1530/EJE-14-0596)

137 Calderon B, Huerta L, Galindo J, Gonzalez Casbas JM, EscobarMorreale HF, Martin-Hidalgo A \& Botella-Carretero JI. Lack of improvement of sperm characteristics in obese males after obesity surgery despite the beneficial changes observed in reproductive hormones. Obesity Surgery 201929 2045-2050. (https://doi. org/10.1007/s11695-019-03798-4)

138 Lee Y, Dang JT, Switzer N, Yu J, Tian C, Birch DW \& Karmali S. Impact of bariatric surgery on male sex hormones and sperm quality: a systematic review and meta-analysis. Obesity Surgery 201929 334-346. (https://doi.org/10.1007/s11695-018-3557-5)

139 Mirone V, Debruyne F, Dohle G, Salonia A, Sofikitis N, Verze P, Fode M, Chapple C \& URO-TRAM Working Group. European Association of Urology position statement on the role of the urologist in the management of male hypogonadism and testosterone therapy. European Urology 201772 164-167. (https://doi. org/10.1016/j.eururo.2017.02.022)

140 Cole AP, Hanske J, Jiang W, Kwon NK, Lipsitz SR, Kathrins M, Learn PA, Sun M, Haider AH, Basaria S et al. Impact of testosterone replacement therapy on thromboembolism, heart disease and obstructive sleep apnoea in men. BJU International $2018 \mathbf{1 2 1}$ 811-818. (https://doi.org/10.1111/bju.14149)

141 Gagliano-Juca T \& Basaria S. Testosterone replacement therapy and cardiovascular risk. Nature Reviews: Cardiology 201916 555-574. (https://doi.org/10.1038/s41569-019-0211-4)

142 Caliber M \& Hackett G. Important lessons about testosterone therapy-weight loss vs. testosterone therapy for symptom resolution, classical vs. functional hypogonadism, and shortterm vs. lifelong testosterone therapy. Aging Male 2019 1-7. (https://doi.org/10.1080/1 3685538.2018.1549211)

143 Rastrelli G, Corona G, Mannucci E \& Maggi M. Factors affecting spermatogenesis upon gonadotropin-replacement therapy: a meta-analytic study. Andrology 20142 794-808. (https://doi. org/10.1111/andr.262)

144 Alvarez-Blasco F, Botella-Carretero JI, San Millan JL \& EscobarMorreale HF. Prevalence and characteristics of the polycystic ovary syndrome in overweight and obese women. Archives of Internal Medicine 2006166 2081-2086. (https://doi.org/10.1001/ archinte.166.19.2081)

145 Escobar-Morreale HF, Santacruz E, Luque-Ramirez M \& Botella Carretero JI. Prevalence of 'obesity-associated gonadal dysfunction' 
in severely obese men and women and its resolution after bariatric surgery: a systematic review and meta-analysis. Human Reproduction Update 201723 390-408. (https://doi.org/10.1093/humupd/dmx012)

146 McCartney CR, Blank SK, Prendergast KA, Chhabra S, Eagleson CA, Helm KD, Yoo R, Chang RJ, Foster CM, Caprio S et al. Obesity and sex steroid changes across puberty: evidence for marked hyperandrogenemia in pre- and early pubertal obese girls. Journal of Clinical Endocrinology and Metabolism 200792 430-436. (https://doi.org/10.1210/jc.2006-2002)

147 Pasquali R, Diamanti-Kandarakis E \& Gambineri A. MANAGEMENT of ENDOCRINE DISEASE: Secondary polycystic ovary syndrome: theoretical and practical aspects. European Journal of Endocrinology 2016175 R157-R169. (https://doi.org/10.1530/EJE-16-0374)

148 Burt Solorzano CM, Knudsen KL, Anderson AD, Hutchens EG, Collins JS, Patrie JT, Marshall JC \& McCartney CR. Insulin resistance, hyperinsulinemia, and LH: relative roles in peripubertal obesity-associated hyperandrogenemia. Journal of Clinical Endocrinology and Metabolism 2018103 2571-2582. (https://doi. org/10.1210/jc.2018-00131)

149 Talmor A \& Dunphy B. Female obesity and infertility. Best Practice and Research: Clinical Obstetrics and Gynaecology 201529 498-506. (https://doi.org/10.1016/j.bpobgyn.2014.10.014)

150 Rotterdam ESHRE/ASRM-Sponsored PCOS consensus workshop group. Revised 2003 consensus on diagnostic criteria and long-term health risks related to polycystic ovary syndrome (PCOS). Human Reproduction 200419 41-47. (https://doi.org/10.1093/humrep/ deh098)

151 Dunaif A \& Fauser BC. Renaming PCOS - a two-state solution. Journal of Clinical Endocrinology and Metabolism 201398 4325-4328. (https:// doi.org/10.1210/jc.2013-2040)

152 Pasquali R, Zanotti L, Fanelli F, Mezzullo M, Fazzini A, Morselli Labate AM, Repaci A, Ribichini D \& Gambineri A. Defining hyperandrogenism in women with polycystic ovary syndrome: a challenging perspective. Journal of Clinical Endocrinology and Metabolism 2016101 2013-2022. (https://doi.org/10.1210/jc.2015-4009)

153 Legro RS, Arslanian SA, Ehrmann DA, Hoeger KM, Murad MH, Pasquali R, Welt CK \& Endocrine Society. Diagnosis and treatment of polycystic ovary syndrome: an Endocrine Society clinical practice guideline. Journal of Clinical Endocrinology and Metabolism 201398 4565-4592. (https://doi.org/10.1210/jc.2013-2350)

154 Munzker J, Hofer D, Trummer C, Ulbing M, Harger A, Pieber T, Owen L, Keevil B, Brabant G, Lerchbaum E et al. Testosterone to dihydrotestosterone ratio as a new biomarker for an adverse metabolic phenotype in the polycystic ovary syndrome. Journal of Clinical Endocrinology and Metabolism 2015100 653-660. (https://doi. org/10.1210/jc.2014-2523)

155 Conway G, Dewailly D, Diamanti-Kandarakis E, Escobar-Morreale HF, Franks S, Gambineri A, Kelestimur F, Macut D, Micic D, Pasquali R et al. The polycystic ovary syndrome: a position statement from the European Society of Endocrinology. European Journal of Endocrinology 2014171 P1-29. (https://doi.org/10.1530/EJE-14-0253)

156 O'Reilly MW, Taylor AE, Crabtree NJ, Hughes BA, Capper F, Crowley RK, Stewart PM, Tomlinson JW \& Arlt W. Hyperandrogenemia predicts metabolic phenotype in polycystic ovary syndrome: the utility of serum androstenedione. Journal of Clinical Endocrinology and Metabolism 201499 1027-1036. (https:// doi.org/10.1210/jc.2013-3399)

157 Salley KE, Wickham EP, Cheang KI, Essah PA, Karjane NW \& Nestler JE. Glucose intolerance in polycystic ovary syndrome - a position statement of the Androgen Excess Society. Journal of Clinical Endocrinology and Metabolism 200792 4546-4556. (https://doi. org/10.1210/jc.2007-1549)

158 Moran LJ, Pasquali R, Teede HJ, Hoeger KM \& Norman RJ. Treatment of obesity in polycystic ovary syndrome: a position statement of the Androgen Excess and Polycystic Ovary Syndrome Society. Fertility and Sterility 200992 1966-1982. (https://doi.org/10.1016/j. fertnstert.2008.09.018)
159 Yildiz BO. Approach to the patient: contraception in women with polycystic ovary syndrome. Journal of Clinical Endocrinology and Metabolism 2015100 794-802. (https://doi.org/10.1210/jc.2014-3196)

160 Stegeman BH, de Bastos M, Rosendaal FR, van Hylckama Vlieg A, Helmerhorst FM, Stijnen T \& Dekkers OM. Different combined oral contraceptives and the risk of venous thrombosis: systematic review and network meta-analysis. BMJ 2013347 f5298. (https://doi. org/10.1136/bmj.f5298)

161 Norman RJ, Flight IH \& Rees MC. Oestrogen and progestogen hormone replacement therapy for peri-menopausal and postmenopausal women: weight and body fat distribution. Cochrane Database of Systematic Reviews 20002 Cd001018. (https://doi. org/10.1002/14651858.CD001018)

162 Dieguez C \& Casanueva FF. Influence of metabolic substrates and obesity on growth hormone secretion. Trends in Endocrinology and Metabolism 19956 55-59. (https://doi.org/10.1016/1043-2760(94)00206-j)

163 Williams T, Berelowitz M, Joffe SN, Thorner MO, Rivier J, Vale W \& Frohman LA. Impaired growth hormone responses to growth hormone-releasing factor in obesity. A pituitary defect reversed with weight reduction. New England Journal of Medicine 1984311 1403-1407. (https://doi.org/10.1056/ NEJM198411293112203)

164 Giustina A, Barkan A, Chanson P, Grossman A, Hoffman A, Ghigo E, Casanueva F, Colao A, Lamberts S, Sheppard M et al. Guidelines for the treatment of growth hormone excess and growth hormone deficiency in adults. Journal of Endocrinological Investigation $2008 \mathbf{3 1}$ 820-838. (https://doi.org/10.1007/bf03349263)

165 Cordido F, Casanueva FF, Vidal JI \& Dieguez C. Study of insulinlike growth factor I in human obesity. Hormone Research 199136 187-191. (https://doi.org/10.1159/000182158)

166 Galli G, Pinchera A, Piaggi P, Fierabracci P, Giannetti M, Querci G, Scartabelli G, Manetti L, Ceccarini G, Martinelli S et al. Serum insulin-like growth factor-1 concentrations are reduced in severely obese women and raise after weight loss induced by laparoscopic adjustable gastric banding. Obesity Surgery 201222 1276-1280. (https://doi.org/10.1007/s11695-012-0669-1)

167 Casanueva FF. Physiology of growth hormone secretion and action. Endocrinology and Metabolism Clinics of North America 199221 483-517. (https://doi.org/10.1016/S0889-8529(18)30199-3)

168 Postma MR, van Beek AP, Jonsson PJ, van Bunderen CC, Drent ML, Mattsson AF \& Camacho-Hubner C. Improvements in body composition after 4 years of growth hormone treatment in adult-onset hypopituitarism compared to age-matched controls. Neuroendocrinology 2019109 131-140. (https://doi. org/10.1159/000499430)

169 Krzizek EC, Brix JM, Herz CT, Kopp HP, Schernthaner GH, Schernthaner G \& Ludvik B. Prevalence of micronutrient deficiency in patients with morbid obesity before bariatric surgery. Obesity Surgery 201828 643-648. (https://doi.org/10.1007/s11695-0172902-4)

170 Ong MW, Tan CH \& Cheng AKS. Prevalence and determinants of vitamin D deficiency among the overweight and obese Singaporeans seeking weight management including bariatric surgery: a relationship with bone health. Obesity Surgery 201828 2305-2312. (https://doi.org/10.1007/s11695-018-3142-y)

171 Hewitt S, Aasheim ET, Sovik TT, Jahnsen J, Kristinsson J, Eriksen EF $\&$ Mala T. Relationships of serum 25-hydroxyvitamin D, ionized calcium and parathyroid hormone after obesity surgery. Clinical Endocrinology 201888 372-379. (https://doi.org/10.1111/cen.13531)

172 Walsh JS, Bowles S \& Evans AL. Vitamin D in obesity. Current Opinion in Endocrinology, Diabetes, and Obesity 201724 389-394. (https://doi. org/10.1097/MED.0000000000000371)

173 Agbaht K, Mercan Y, Kutlu S, Alpdemir MF \& Sezgin T. Obesity with and without metabolic syndrome: do vitamin D and thyroid autoimmunity have a role? Diabetes Research and Clinical Practice 2014106 27-34. (https://doi.org/10.1016/j.diabres.2014.08.001) 
174 Wimalawansa SJ. Vitamin D and cardiovascular diseases: causality. Journal of Steroid Biochemistry and Molecular Biology 2018175 29-43. (https://doi.org/10.1016/j.jsbmb.2016.12.016)

175 Brar PC, Contreras M, Fan X \& Visavachaipan N. Effect of one time high dose 'stoss therapy' of vitamin D on glucose homeostasis in high risk obese adolescents. Archives of Endocrinology and Metabolism 201862 193-200. (https://doi.org/10.20945/23593997000000024)

176 Manson JE, Cook NR, Lee IM, Christen W, Bassuk SS, Mora S, Gibson H, Gordon D, Copeland T, D'Agostino D et al. Vitamin D supplements and prevention of cancer and cardiovascular disease. New England Journal of Medicine 2019380 33-44. (https://doi. org/10.1056/NEJMoa1809944)

177 Jin J, Robinson AV, Hallowell PT, Jasper JJ, Stellato TA \& Wilhem SM. Increases in parathyroid hormone (PTH) after gastric bypass surgery appear to be of a secondary nature. Surgery $2007 \mathbf{1 4 2} 914-920$; discussion 914. (https://doi.org/10.1016/j.surg.2007.09.023)

178 Wei JH, Lee WJ, Chong K, Lee YC, Chen SC, Huang PH \& Lin SJ. High incidence of secondary hyperparathyroidism in bariatric patients: comparing different procedures. Obesity Surgery 201828 798-804. (https://doi.org/10.1007/s11695-017-2932-y)

179 Shapses SA, Lee EJ, Sukumar D, Durazo-Arvizu R \& Schneider SH. The effect of obesity on the relationship between serum parathyroid hormone and 25-hydroxyvitamin D in women. Journal of Clinical Endocrinology and Metabolism 201398 E886-E890. (https://doi. org/10.1210/jc.2012-3369)

180 Grethen E, McClintock R, Gupta CE, Jones R, Cacucci BM, Diaz D, Fulford AD, Perkins SM, Considine RV \& Peacock M. Vitamin D and hyperparathyroidism in obesity. Journal of Clinical Endocrinology and Metabolism 201196 1320-1326. (https://doi. org/10.1210/jc.2010-2202)

181 Walsh JS, Evans AL, Bowles S, Naylor KE, Jones KS, Schoenmakers I, Jacques RM \& Eastell R. Free 25-hydroxyvitamin D is low in obesity, but there are no adverse associations with bone health. American Journal of Clinical Nutrition 2016103 1465-1471. (https://doi. org/10.3945/ajcn.115.120139)

182 Bikle DD \& Schwartz J. Vitamin D binding protein, total and free vitamin D levels in different physiological and pathophysiological conditions. Frontiers in Endocrinology 201910 317. (https://doi. org/10.3389/fendo.2019.00317)

183 Schafer AL. Vitamin D and intestinal calcium transport after bariatric surgery. Journal of Steroid Biochemistry and Molecular Biology 2017173 202-210. (https://doi.org/10.1016/j.jsbmb.2016.12.012)

184 Bassatne A, Chakhtoura M, Saad R \& Fuleihan GE. Vitamin D supplementation in obesity and during weight loss: a review of randomized controlled trials. Metabolism: Clinical and Experimental 201992 193-205. (https://doi.org/10.1016/j.metabol.2018.12.010)

185 Maffei M, Halaas J, Ravussin E, Pratley RE, Lee GH, Zhang Y, Fei H, Kim S, Lallone R \& Ranganathan S. Leptin levels in human and rodent: measurement of plasma leptin and ob RNA in obese and weight-reduced subjects. Nature Medicine 19951 1155-1161. (https:// doi.org/10.1038/nm1195-1155)

186 Farooqi IS \& O'Rahilly S. 20 years of leptin: human disorders of leptin action. Journal of Endocrinology 2014223 T63-T70. (https:// doi.org/10.1530/JOE-14-0480)

187 Montague CT, Farooqi IS, Whitehead JP, Soos MA, Rau H, Wareham NJ, Sewter CP, Digby JE, Mohammed SN, Hurst JA et al. Congenital leptin deficiency is associated with severe earlyonset obesity in humans. Nature 1997387 903-908. (https://doi. org/10.1038/43185)

188 Farooqi IS, Matarese G, Lord GM, Keogh JM, Lawrence E, Agwu C, Sanna V, Jebb SA, Perna F, Fontana S et al. Beneficial effects of leptin on obesity, T cell hyporesponsiveness, and neuroendocrine/ metabolic dysfunction of human congenital leptin deficiency. Journal of Clinical Investigation 2002110 1093-1103. (https://doi. org/10.1172/JCI15693)
189 Clement K, Vaisse C, Lahlou N, Cabrol S, Pelloux V, Cassuto D, Gourmelen M, Dina C, Chambaz J, Lacorte JM et al. A mutation in the human leptin receptor gene causes obesity and pituitary dysfunction. Nature 1998392 398-401. (https://doi. org/10.1038/32911)

190 Tschop M, Weyer C, Tataranni PA, Devanarayan V, Ravussin E \& Heiman ML. Circulating ghrelin levels are decreased in human obesity. Diabetes 200150 707-709. (https://doi.org/10.2337/ diabetes.50.4.707)

191 Pournaras DJ \& le Roux CW. Ghrelin and metabolic surgery. International Journal of Peptides 2010 2010. (https://doi. org/10.1155/2010/217267)

192 Haqq AM, Farooqi IS, O'Rahilly S, Stadler DD, Rosenfeld RG, Pratt KL, LaFranchi SH \& Purnell JQ. Serum ghrelin levels are inversely correlated with body mass index, age, and insulin concentrations in normal children and are markedly increased in Prader-Willi syndrome. Journal of Clinical Endocrinology and Metabolism $2003 \mathbf{8 8}$ 174-178. (https://doi.org/10.1210/jc.2002-021052)

193 Thomas RM, Ruel E, Shantavasinkul PC \& Corsino L. Endocrine hypertension: an overview on the current etiopathogenesis and management options. World Journal of Hypertension 20155 14-27. (https://doi.org/10.5494/wjh.v5.i2.14)

194 Rossi GP, Bernini G, Caliumi C, Desideri G, Fabris B, Ferri C, Ganzaroli C, Giacchetti G, Letizia C, Maccario M et al. A prospective study of the prevalence of primary aldosteronism in 1,125 hypertensive patients. Journal of the American College of Cardiology 200648 2293-2300. (https://doi.org/10.1016/j.jacc.2006.07.059)

195 Funder JW, Carey RM, Fardella C, Gomez-Sanchez CE, Mantero F, Stowasser M, Young WF, Montori VM \& Endocrine Society. Case detection, diagnosis, and treatment of patients with primary aldosteronism: an endocrine society clinical practice guideline. Journal of Clinical Endocrinology and Metabolism 200893 3266-3281. (https://doi.org/10.1210/jc.2008-0104)

196 Streeten DH, Anderson Jr GH, Howland T, Chiang R \& Smulyan H. Effects of thyroid function on blood pressure. Recognition of hypothyroid hypertension. Hypertension 198811 78-83. (https://doi. org/10.1161/01.hyp.11.1.78)

197 Calina D, Docea AO, Golokhvast KS, Sifakis S, Tsatsakis A \& Makrigiannakis A. Management of endocrinopathies in pregnancy: a review of current evidence. International Journal of Environmental Research and Public Health 201916 E781. (https://doi.org/10.3390/ ijerph16050781)

198 Lutsiv O, Mah J, Beyene J \& McDonald SD. The effects of morbid obesity on maternal and neonatal health outcomes: a systematic review and meta-analyses. Obesity Reviews 201516 531-546. (https:// doi.org/10.1111/obr.12283)

199 Moleti M, Trimarchi F \& Vermiglio F. Thyroid physiology in pregnancy. Endocrine Practice 201420 589-596. (https://doi. org/10.4158/EP13341.RA)

200 Demey-Ponsart E, Foidart JM, Sulon J, Sodoyez JC. Serum CBG, free and total cortisol and circadian patterns of adrenal function in normal pregnancy. Journal of Steroid Biochemistry 198216 165-169. (https://doi.org/10.1016/0022-4731(82)90163-7)

201 Stirrat LI, Walker JJ, Stryjakowska K, Jones N, Homer NZM, Andrew R, Norman JE, Lightman SL \& Reynolds RM. Pulsatility of glucocorticoid hormones in pregnancy: changes with gestation and obesity. Clinical Endocrinology $2018 \mathbf{8 8}$ 592-600. (https://doi. org/10.1111/cen.13548)

202 Zitouni H, Raguema N, Gannoun MBA, Hebert-Stutter M, Zouari I, Maleh W, Faleh R, Letaifa DB, Almawi WY, Fournier T et al. Impact of obesity on the association of active renin and plasma aldosterone concentrations, and aldosterone-to-renin ratio with preeclampsia. Pregnancy Hypertension 201814 139-144. (https://doi.org/10.1016/j. preghy.2018.09.007)

203 Salles JP. Bone metabolism during pregnancy. Annales $d^{\prime}$ Endocrinologie 201677 163-168. (https://doi.org/10.1016/j.ando.2016.04.004) 
204 Cruz S, de Matos AC, da Cruz SP, Pereira S, Saboya C \& Ramalho A. Maternal anthropometry and its relationship with the nutritional status of vitamin D, calcium, and parathyroid hormone in pregnant women after Roux-en-Y gastric bypass. Obesity Surgery 201828 3116-3124. (https://doi.org/10.1007/s11695-018-3331-8)

205 Coupaye M, Legardeur H, Sami O, Calabrese D, Mandelbrot L \& Ledoux S. Impact of Roux-en-Y gastric bypass and sleeve gastrectomy on fetal growth and relationship with maternal nutritional status. Surgery for Obesity and Related Diseases 201814 1488-1494. (https:// doi.org/10.1016/j.soard.2018.07.014)

206 Carle A, Pedersen IB, Knudsen N, Perrild H, Ovesen L, Andersen S $\&$ Laurberg P. Hypothyroid symptoms fail to predict thyroid insufficiency in old people: a population-based case-control study. American Journal of Medicine 2016129 1082-1092. (https://doi. org/10.1016/j.amjmed.2016.06.013)

207 Rodondi N, den Elzen WP, Bauer DC, Cappola AR, Razvi S, Walsh JP, Asvold BO, Iervasi G, Imaizumi M, Collet TH et al. Subclinical hypothyroidism and the risk of coronary heart disease and mortality. JAMA 2010304 1365-1374. (https://doi.org/10.1001/ jama.2010.1361)

208 Vitale G, Cesari M \& Mari D. Aging of the endocrine system and its potential impact on sarcopenia. European Journal of Internal Medicine 201635 10-15. (https://doi.org/10.1016/j. ejim.2016.07.017)

209 Maimoun L, Mura T, Leprieur E, Avignon A, Mariano-Goulart D \& Sultan A. Impact of obesity on bone mass throughout adult life: influence of gender and severity of obesity. Bone 201690 23-30. (https://doi.org/10.1016/j.bone.2015.11.020)

210 Davis SR, Castelo-Branco C, Chedraui P, Lumsden MA, Nappi RE, Shah D, Villaseca P \& Writing Group of the International Menopause
Society for World Menopause Day 2012. Understanding weight gain at menopause. Climacteric 201215 419-429. (https://doi.org/10.3109 /13697137.2012.707385)

211 Constantine GD, Kessler G, Graham S \& Goldstein SR. Increased incidence of endometrial cancer following the Women's Health Initiative: an assessment of risk factors. Journal of Women's Health 201928 237-243. (https://doi.org/10.1089/jwh.2018.6956)

212 Snyder PJ, Bhasin S, Cunningham GR, Matsumoto AM, StephensShields AJ, Cauley JA, Gill TM, Barrett-Connor E, Swerdloff RS Wang C et al. Effects of testosterone treatment in older men. New England Journal of Medicine 2016374 611-624. (https://doi. org/10.1056/NEJMoa1506119)

213 Mohler 3rd ER, Ellenberg SS, Lewis CE, Wenger NK, Budoff MJ, Lewis MR, Barrett-Connor E, Swerdloff RS, Stephens-Shields A, Bhasin S et al. The effect of testosterone on cardiovascular biomarkers in the testosterone trials. Journal of Clinical Endocrinology and Metabolism 2018 103 681-688. (https://doi.org/10.1210/jc.2017-02243)

214 Spitzer M, Huang G, Basaria S, Travison TG \& Bhasin S. Risks and benefits of testosterone therapy in older men. Nature Reviews. Endocrinology 20139 414-424. (https://doi.org/10.1038/ nrendo.2013.73)

215 Hoogendijk EO, Deeg DJ, Poppelaars J, van der Horst M, Broese van Groenou MI, Comijs HC, Pasman HR, van Schoor NM, Suanet B, Thomése F et al. The Longitudinal Aging Study Amsterdam: cohort update 2016 and major findings. European Journal of Epidemiology 201631 927-945. (https://doi.org/10.1007/ s10654-016-0192-0)

216 Clegg A \& Hassan-Smith Z. Frailty and the endocrine system. Lancet: Diabetes and Endocrinology 20186 743-752. (https://doi.org/10.1016/ S2213-8587(18)30110-4)

Received 6 November 2019

Accepted 8 November 2019 